University of Louisville

ThinkIR: The University of Louisville's Institutional Repository

Electronic Theses and Dissertations

8-2012

\title{
Parental engagement on student academic self-efficacy and educational attainment expectation for immigrant youth.
}

Casey N. Griffith

University of Louisville

Follow this and additional works at: https://ir.library.louisville.edu/etd

\section{Recommended Citation}

Griffith, Casey N., "Parental engagement on student academic self-efficacy and educational attainment expectation for immigrant youth." (2012). Electronic Theses and Dissertations. Paper 533.

https://doi.org/10.18297/etd/533

This Master's Thesis is brought to you for free and open access by ThinkIR: The University of Louisville's Institutional Repository. It has been accepted for inclusion in Electronic Theses and Dissertations by an authorized administrator of ThinkIR: The University of Louisville's Institutional Repository. This title appears here courtesy of the author, who has retained all other copyrights. For more information, please contact thinkir@louisville.edu. 


\title{
PARENTAL ENGAGEMENT ON STUDENT ACADEMIC SELF-EFFICACY AND EDUCATIONAL ATTAINMENT EXPECTATION FOR IMMIGRANT YOUTH
}

\section{By}

\author{
Casey N. Griffith
}

\author{
A Thesis \\ Submitted to the Faculty of the \\ College of Arts and Sciences of the University of Louisville \\ in Partial Fulfillment of the Requirements \\ for the Degree of
}

\author{
Master of Arts \\ Department of Sociology \\ University of Louisville \\ Louisville, Kentucky
}

August 2012 


\title{
PARENTAL ENGAGEMENT ON STUDENT ACADEMIC SELF-EFFICACY AND EDUCATIONAL ATTAINMENT EXPECTATION FOR IMMIGRANT YOUTH
}

\section{By}

Casey N. Griffith

A Thesis Approved on

July 19, 2012

by the following Thesis Committee:

\author{
Latrice Best, Thesis Director
}

Jake Gross

Robert Carini 


\section{DEDICATION}

This thesis is dedicated to my parents, Gail and Dave Griffith, who have supported me throughout my academic career. 


\section{ACKNOWLEDGMENTS}

I would like to thank my thesis chair, Dr. Latrica Best, for her valuable guidance throughout the thesis process. Her direction and patience greatly contributed to a successful thesis completion. I would also like to thank my additional committee members, Dr. Bob Carini and Dr. Jake Gross, for their diligence in a short amount of time. They provided important insight for my work. Additionally, I want to thank my family and friends (near and far) for their patience and encouragement during my time in graduate school. Finally, I would like to thank Highland Coffee Company, where much of my thesis was written, for their delicious drinks and amiable work environment. 


\begin{abstract}
PARENTAL ENGAGEMENT ON STUDENT ACADEMIC SELF-EFFICACY AND EDUCATIONAL ATTAINMENT EXPECTATION FOR IMMIGRANT YOUTH Casey N. Griffith
\end{abstract}

July 19,2012

With the increase of immigration to the United States, immigrant children have a unique position in the education system. Immigrant parents influence their children through different academic engagement practices. It is important to understand how parents impact students' academic experiences. Employing the Educational Longitudinal Study of 2002, statistical analyses evaluated a sample of 2,514 high school sophomore immigrant students. The impact of parental engagement on the dependent variables were also compared between native language groups to learn whether or not specific cultural engagement practices impact student self-efficacy and attainment expectation differently. Findings revealed that parental engagement impacts academic self-efficacy and educational attainment expectation. Native language group differences indicated that the impact of parental engagement on the dependent variables was often greater for the Asian groups than Spanish and English speaking immigrants. Educators can use the information gained from this study to help immigrant parents improve their children's academic experiences. 


\section{TABLE OF CONTENTS}

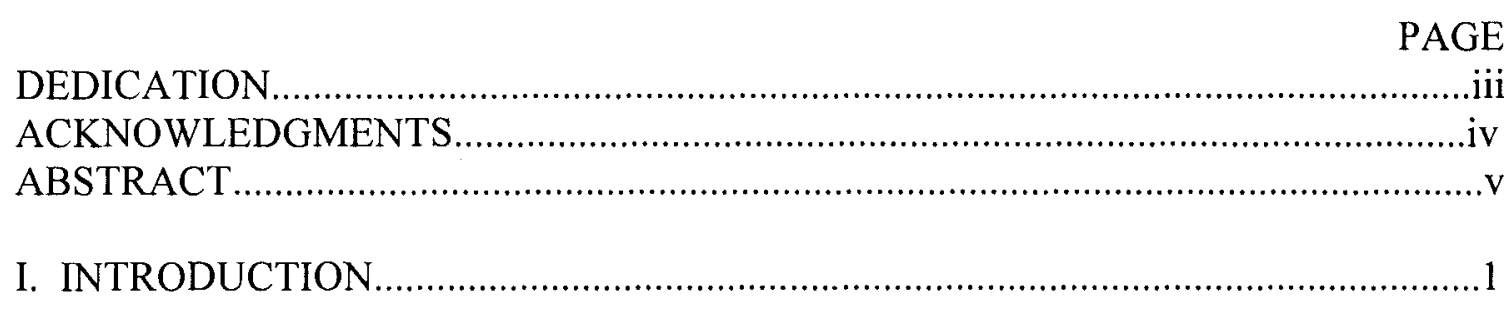

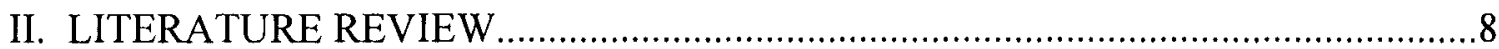

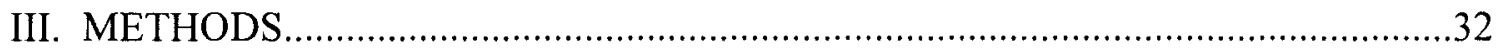

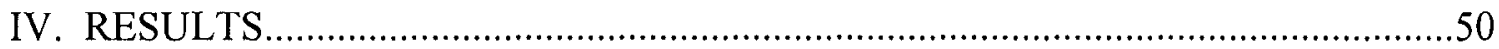

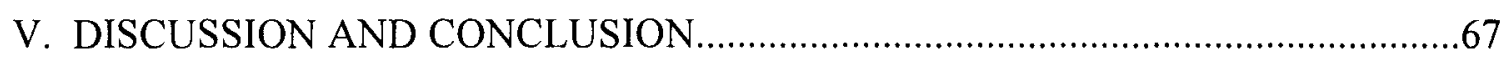

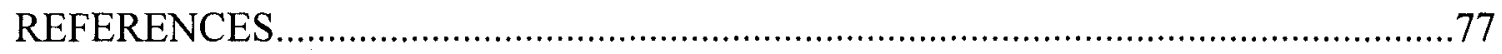

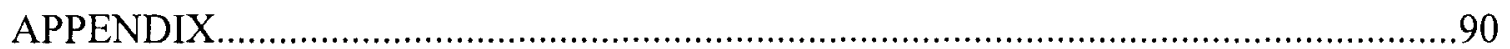

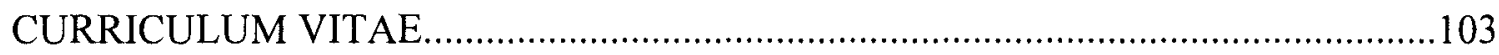




\section{CHAPTER I}

\section{INTRODUCTION}

The number of immigrants is rapidly growing in the United States and there are increasing numbers of immigrant children enrolled in schools across the country (Capps et al. 2005). Immigrants bring specific cultural values and norms from their home country as they integrate into U.S. society. Cultural aspects specific to an immigrant's home country can differ from the structure of the U.S. education system and can leave students struggling to figure out their position in U.S. society as they straddle two different worlds of school and home. Subsequently, students may have a poor academic experience.

The changing demographics due to the influx of immigrants to the U.S. affect the country's institutions as well as personal interactions. Projections estimate that Hispanic and Asian populations will double between 2000 and 2050 due to immigration and reproduction (Ortman and Guarneri 2009). The most recent movement of immigrants migrating to the U.S. is largely made up of Mexican or East Asian groups, but the diversity of immigrants has begun to expand. Many immigrants are now arriving from other parts of Latin America and Asia, the Caribbean, and Europe (Grieco et al. 2012).

The 2000 census reports that one in five children under 18 is a child of immigrants (Capps et al. 2005). These children will enter the workforce and political 
arena as they grow older, and will become leaders of the country. They will also become consumers of products that are sold in the country. The changing demographics of the U.S. also impacts interactions between people and the national discussion of multiculturalism.

Education is the first system this group of children enters, so it is important for immigrant children to have a positive academic career. Because immigrant children have backgrounds that are unique from native children, the education system must adapt with the changing demographics in order to provide for the needs of ethnically unique students. Educators must learn how to teach immigrant children whose cultural background is vastly different from native children. The connection between school and home must also change in order to maximize the potential of students who live in an ethnically different home environment.

Parents play an important role in helping children maneuver through the acculturation process in school and home. Literature has shown that parental engagement has a positive impact on students' academic achievement, among immigrant and native students (Lahaie 2008; Schneider and Lee 1990; Suarez-Orozco, Bang and Onaga 2010). School performance increases when parents are more engaged in their children's studies.

There is a body of literature that explains how children are influenced by multiple entities - parents, teachers, peers, and community (Bong 2008; Bozick et al. 2010; Colvin and Schlosser 1997; Eccles, Wigfield, and Schiefele 1998; GonzalezDeHass et al. 2005; Grolnick and Slowiaczek 1994; Ogbu and Simons 1998; Schlosser 1992; Schunk and Carbonari 1984; Sciarra and Ambrosino 2011; Sewell, Haller, and 
Portes 1969). These influencing members often intersect, weaving together the full story of a student's academic life. This study focuses on the relationship between students and one influencing entity - parents. Parents provide a student's connection between school and home by engaging in academic tasks and conversations at home and also by participating in activities at school. This engagement sends messages to a student about the importance of education, and a student makes educational decisions based on the influencing messages received from the parents.

Parental engagement comes in different forms; I have chosen to examine athome resources, household rules, and academic interaction with children. Resources include supplies and learning tools that are available at home that benefit a child's education, such as books or a computer. Rules are those boundaries set by parents to regulate a child's habits. Interaction consists of communication between a parent and child regarding school-related topics.

Achievement, self-efficacy, and educational attainment expectations are important in understanding a student's academic experience. Most research has been conducted to explain how parental engagement impacts academic achievement, which is why the present study focuses on parental engagement on a child's academic selfefficacy and educational attainment expectation. Because previous research has demonstrated the connection between parental engagement and achievement, academic self-efficacy and educational attainment expectation serve as process indicators of achievement (Ewell and Jones 1993). Diagram 1, below, illustrates the model of parental engagement and achievement with self-efficacy and attainment expectation as mediating variables. 
Diagram 1: Model of Parental Engagement to Achievement with Academic Self-Efficacy and Educational Attainment Expectation as Process Indicators

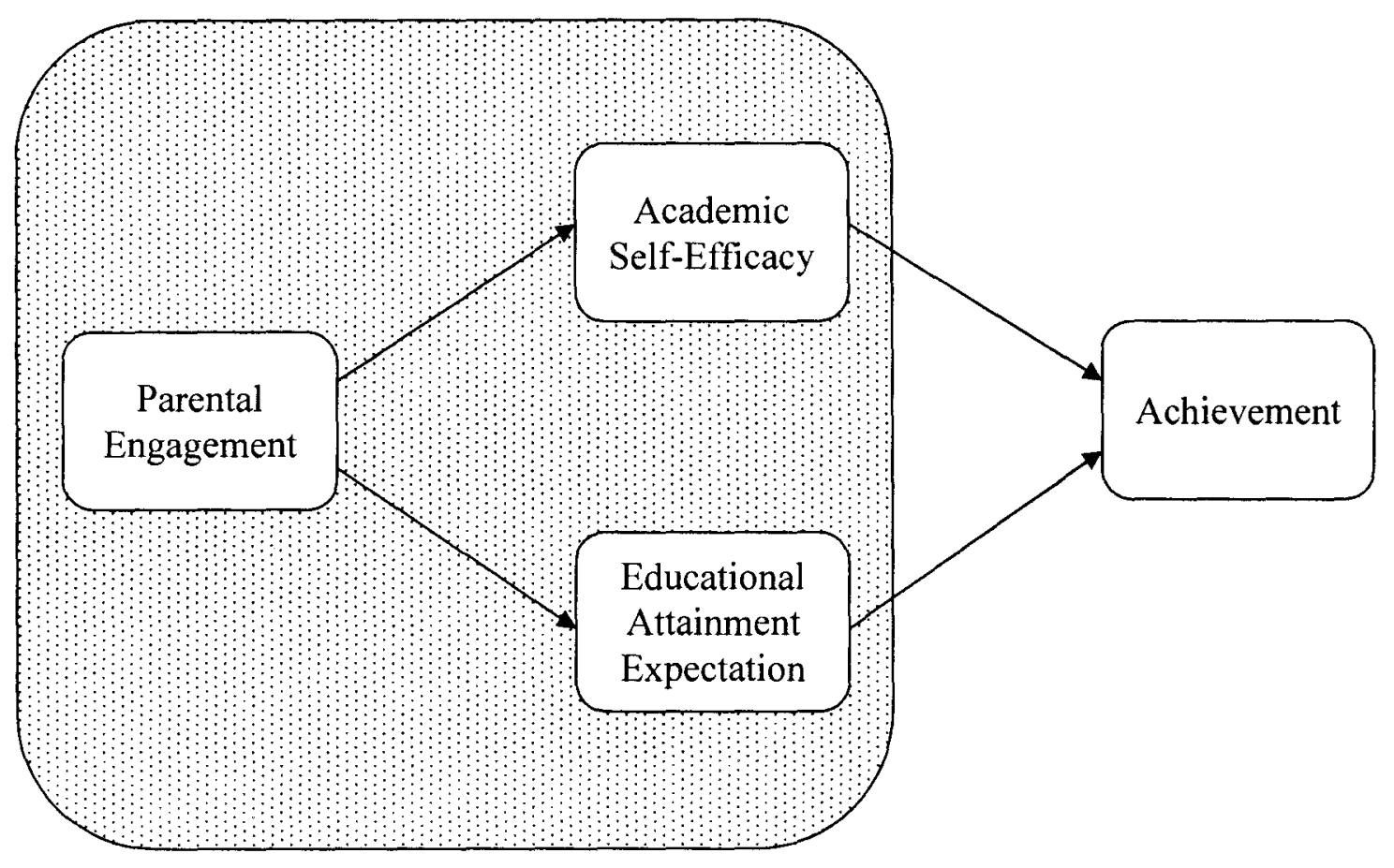

These variables are process indicators because they contribute to the end result of achievement, and it is important to understand the relationship between parental engagement and the process indicators as it describes part of a larger story. This study, then, focused on the connection between parental engagement with self-efficacy and attainment expectation. The shaded area on the diagram highlights the focus of the study.

Specifically, the effects of at-home resources, household rules, and academic interaction on immigrant students' academic self-efficacy and educational attainment expectation were analyzed. These effects were compared between ethnic groups in order to learn how parents in different groups engage with their children. This study was different from previous literature because it examined between-group differences in 
parenting styles for a wide range of immigrant groups, not between native and immigrant students. Studies that have used this data set have compared specific immigrant groups with native counterparts or with white natives.

The topic of parental engagement on children's academic self-efficacy and educational attainment expectation, specifically for immigrants, is an important one to study. It provides an opportunity for an improved connection between school and home. Parents may be able to develop new forms with which to influence their children in ways that will better their academic confidence and future. Schools may be able to work with parents to support students through cultural strategies that will foster the students' potential. Overall, parents may not be aware of the ways in which their parenting impacts the child in school. Learning about these parenting forms and cultural influences can provide new directions for schools and parents to take in bettering students' academic experiences.

\section{Hypotheses}

I hypothesized that the presence of parental engagement through resources, rules, and interaction would lead to a higher academic self-efficacy in a student. Parent involvement has been shown to foster positive beliefs about students' perception of their capabilities (Bong 2008; Gonzalez-DeHass et al. 2005; Grolnick and Slowiaczek 1994). In the psychology field, overprotective mothering leads to a child's negative selfconfidence (Want and Kleitman 2006), while nurturing parenting styles lead to a positive self-confidence (Moss and St-Laurent 2001). 
I suggested that academic parental engagement would lead to a similar direction in a student's academic self-efficacy. I predicted that resources, rules, and interaction would also lead to a higher educational attainment expectation for a student. Research shows that at-home academic parental engagement has a positive effect on children's educational expectations for themselves (Bozick et al. 2010; Hao and Bonstead-Bruns 1998; Sewell et al. 1969). Encouragement to attend college from parents often lead students to hold a high educational attainment expectation for themselves (Louie 2001).

When comparing ethnic groups, I expected to find that the way resources, interaction, and rules impact a student's efficacy and attainment expectation would differ between native language groups. Research (often qualitative studies) suggests that there are differences in parenting styles between different ethnic groups (Driscoll, Russell and Crockett 2008; Hao and Bonstead-Bruns 1998; Huntsinger and Jose 2009; Ross-Sheriff, Tirmazi and Walsh 2007). Specifically, I predicted that the impact of resources and rules on efficacy and expectation would be greater for East Asian families than the other groups. Previous literature describes many East Asian parents (mostly Chinese, Japanese, and Korean parents) as providing extra-curricular academic activities through private lessons and personal workbooks (Huntsinger and Jose 2009; Schneider and Lee 1990). They also often mandate their children to perform rigorous academic work outside of school (Louie 2001; Schneider and Lee 1990). East Asian students often adhere to their parents' educational values and expectations, so it will be no surprise to learn that the parenting styles relate to students' education outcomes.

I also predicted that the impact of interaction would be greater for Spanish families than other groups. Studies depict Latino parents as transmitting their value of 
education to their children through communication, often due to work schedules that prevent parents from spending a lot of time with their children (Delgado-Gaitin 1992; Kao 2004; Lopez 2001). Communication becomes the easiest way for these parents to influence their children's academic lives, and I predicted that this style of engagement would positively impact academic experiences for the children of these parents. 


\section{CHAPTER II}

\section{LITERATURE REVIEW}

\section{Introduction}

As adults who spend time with children outside of the school setting, parents play an important role in guiding children through their academic years. Parents send children messages about the importance of education through their involvement in academic-related activities (Gonzalez-DeHass et al. 2005). A parent with high levels of parental engagement, through different forms of involvement, communicates to her child that education is important, while a parent with low levels of parental engagement may suggest to her child that education is not significant.

Stemming from Cooley's theory of the "looking glass self," these parental messages are interpreted by the child, and may be received differently than the parent intends them to be taken (Cooley 1902). For example, a parent who works during the evening and is not available to help his child with homework has a low level of parental involvement. The parent may believe that school is important for his child to succeed in life, but his child may interpret his uninvolvement as sending the opposite message. Therefore, a student's perception of parental engagement is more important than a parent's perception. A student may alter behavior based on the message he believes his parent is conveying through the parent's involvement. 
Immigrant parents have unique experiences as they acculturate to U.S. norms, learn the education system, and provide for their family. They also help their children navigate between multiple cultures - the U.S. and the parents' native country. While there are a large number of ethnic groups represented in the U.S. immigrant population, previous literature on educational parenting styles has focused on the Hispanic/Latino and East Asian immigrants. Some research does not specify the different ethnic groups. When authors have identified native countries, they are most often Mexico, China, Japan, and Korea.

\section{Dependent Variables}

Academic Self-Efficacy

Self-efficacy was introduced by Albert Bandura in 1977 as a social learning concept that explains the link between effort and achievement. Bandura defines selfefficacy as judgments people make about their ability to successfully complete a task (Bandura 1977, 1986). Described as an aspect of coping behavior, self-efficacy determines the amount of effort that will be exerted when completing a task, including obstacles that come with performing the task (Bandura 1977; Schunk 1984). Scholars have named self-efficacy in varying ways, such as perceived competence (GonzalezDeHass et al. 2005; Grolnick and Slowiaczek 1994) or perceived cognitive competence (Topor et al. 2010) but adhere to Bandura's description of the concept. The term, selfefficacy, was used in this study.

Applied to the academic setting, students with high self-efficacy believe they are able to accomplish academic tasks such as homework assignments or exams, and are 
likely to spend much time and effort into performing well on an exam or successfully completing a homework assignment. Conversely, students with low self-efficacy may exert less effort or even avoid a homework assignment altogether. Self-efficacy is fluid and can change according to the task (Bandura 1986). A student's self-efficacy might differ between math and English subjects, as well as change based on a specific assignment's level of complexity.

Self-efficacy is an important aspect of a child's academic experience because it is linked to motivation, interest, and achievement. It has been positively associated with academic achievement - higher levels of self-efficacy often indicate higher levels of academic performance (Grolnick and Slowiaczek 1994; Kleitman and Gibson 2011). Students who possess higher levels of self-efficacy are generally more motivated to engage in school because they believe that they can perform well (Bandura 1977). Students are more interested in school activities when they believe they are good at them (Bandura 1994). However, self-efficacy that is too high might lower interest because students become bored with a task that is too easy (Bandura 1994). While it has been hypothesized that previous academic performance influences self-efficacy (Schunk 1984; Weiner 1974), there has been no direct empirical link (Zimmerman, Bandura, and Martinez-Pons 1992).

Interactions from teachers, peers, and parents influence a student's academic self-efficacy. Teachers set expectations and support students through personal interactions and open communication. Student-teacher interactions can increase a student's self-efficacy because the teacher demonstrates confidence in the student and the student becomes more engaged in school (Schlosser 1992). The student's attitude 
toward school becomes positive when she perceives that the teacher supports her (Colvin and Schlosser 1997). Students who observe their peers successfully completing an assignment can increase their confidence in being able to also complete the task (Schunk and Carbonari 1984). Peer groups are likely to share educational values and self-efficacy beliefs, either low or high self-efficacy. As members of peer groups influence each other over time, self-efficacy beliefs become more powerful (Eccles et al. 1998).

The current study focused on parental engagement on a child's academic selfefficacy. Literature reveals that students whose parents are directly involved in their education will foster positive beliefs about education and their academic ability. Parental engagement is shown to be positively linked with the academic motivation of students (Gonzalez-DeHass et al. 2005; Grolnick and Slowiaczek 1994). It also has a positive impact on a child's perception of grades and education, as well as interest in school (Plunkett and Bamaca-Gomez 2003; Plunkett et al. 2009). Bong's (2008) study on South Korean immigrant high schoolers revealed that perceived parental support influenced a student's academic self-efficacy. In fact, parental support was a stronger predictor of self-efficacy than conflict with parents and parental academic pressure, and students' feelings of obligation toward parents negatively affected their self-efficacy (Bong 2008). Overall, literature reports that the engagement of parents has a positive impact on children's academic self-efficacy. This study seeked to explore the different styles of parental engagement and analyze their impact on self-efficacy. 


\section{Educational Attainment Expectation}

Educational attainment expectation is the highest level of schooling one believes he will achieve. Some students may expect to end their schooling at high school, others might have different levels of college, and still others expect to earn a higher degree. It is important to distinguish between expectation and aspiration. Aspirations are possible and desired options available, while expectations are the most likely outcomes

(Gottfredson 1981; Markus and Nurius 1986). The distinction lies in the realistic nature of the choice - an expectation is more realistic than an aspiration. Expectations rely on perception of ability and reflection on past performances, and are better indicators of attainment than aspirations (Andres et al. 2007).

Educational attainment expectation is influenced by a number of variables, including significant people in a student's life, academic performance, and environmental factors. Parents, teachers, and peers send messages to students about the importance of education (Bozick et al. 2010; Sewell et al. 1969). While the influence of people in both the home and school are important, teachers seem to be the most influential figures in forming a student's educational attainment expectation. Sciarra and Ambrosino (2011) found that parental education attainment expectations were less of a predictor of educational status (measured two years out of high school) than teacher and student expectations. In fact, teacher expectation was the strongest predictor of educational status, and the authors suggested that teachers may form expectations for their students based on class achievement and their knowledge of the opportunities in higher education that are available to students (Sciarra and Ambrosino 2011). 
Academic performance encourages or discourages students towards their expectation of performance in higher education (Bozick et al. 2010). Students with higher grades and test scores are more likely than those with lower academic performance to have a college-bound orientation. Environmental factors, such as family socioeconomic status or school attended, indirectly contribute to educational attainment expectations. Socioeconomic status is often linked to at-home resources, parental involvement, and school grades, and those students who are in a high socioeconomic family are more likely to have a high attainment expectation (Bozick et al. 2010, Delgado-Gaitin 1992).

Contemporary longitudinal research has analyzed factors that influence educational attainment expectation and revealed complex patterns of change. Bozick et al. (2010) found that attainment expectation can be fluid, changing from elementary school through the end of high school. Some students surveyed in their longitudinal study changed attainment expectation while other students did not change (Bozick et al. 2010). Other research has proved similar to these findings (Beal and Crockett 2010; Mello 2008).

Scholars also link educational attainment expectation to college attendance. Beal and Crockett (2010) reported that expectations predicted attendance, and learned that participation in extracurricular activities partially mediated this effect. They reasoned that expectations about the future may motivate behavior in different ways (Beal and Crockett 2010; Markus and Nurius 1986). Research suggests that an expectation held for a longer period of a child's life is more ingrained for that student and more likely to act on it (Alexander and Cook 1979; Bozick et al. 2010). 
The different patterns create an interesting story but, overall, an attainment expectation held later in a student's academic career is a better predictor of actual attainment than earlier expectations (Trusty 2000). Bozick and colleagues (2010) reported that students in eleventh grade who had a high educational expectation were three times more likely than those who had a low educational expectation to attend a two-year college, and fourteen times more likely to attend a four-year college. A possible explanation is that students are better aware of their academic and financial situations and have a better understanding of their post-high school opportunities (Sciarra and Ambrosino 2011). Overall, it has been shown that education attainment expectation held in high school is valuable when predicting a student's likelihood of attending college.

It is also theorized that future expectations and present behaviors have a reciprocal relationship (Eccles et al. 2003). Experiences can shape expectations, while expectations might lead to certain actions. Beal and Crockett (2010) found this to be true when their study revealed a bidirectional relationship between educational attainment expectation and participation in extracurricular activities. Analyses showed that each variable impacted the other, suggesting that actions and belief inform one another.

\section{Independent Variables}

\section{Resources}

In-home resources are material possessions or access to learning devices that add to students' education outside of school. Resources can include books, a computer, 
internet access, and personal in-home space, among other things. Students who frequently use a computer at home are more likely than those who don't use a computer at home to feel comfortable and confident in using one at school (Mumtaz 2001). Reading books at home aid in increasing children's reading literacy (Elley 1992). Designating a specific area in the home for students to work on schoolwork provides a place that encourage students to think positively about school (Delgado-Gaitin 1992).

Research has reported that the existence of in-home resources predicts achievement in both immigrant and native families (Lahaie 2008). Increased resources lead to higher academic performance. Further, there is an obvious link between resources and socioeconomic status, as families with more income are able to provide more resources for their children (Delgado-Gaitin 1992).

\section{Latin American Immigrant Families}

Most literature on Spanish-speaking immigrants report on Latin Americans, and, specifically, Mexicans. According to Suarez-Orozco (2001), immigrant homes frequently have a low amount of resources, which impedes students' abilities to complete some homework assignments. Based on qualitative data gathered from six Mexican immigrant families, Delgado-Gaitin (1992) found that the families had a small amount of resources available for the children's academic work. The amount of supplies was limited to the space in each child's backpack, where their supplies were kept. Space was also limited in the Mexican immigrant families' houses. Bedrooms were shared with siblings, and kitchen tables or living room couches also served as study areas 
(Delgado-Gaitin 1992). The lack of in-home space prevented children from having a separate area designated for schoolwork.

\section{East Asian Immigrant Families}

Previous research on East Asian parenting has mostly focused on Chinese or Chinese American families. As described below in the section on "Rules," East Asian parents often enroll their children in extra-curricular private lessons, in areas such as music, computer science, or foreign language, and provide workbooks for students to complete at home (Huntsinger and Jose 2009; Louie 2001; Schneider and Lee 1990). While these examples speak to the way that parents direct their children's time outside of school to be spent on academic tasks, it also shows that many East Asian parents provide a high level of resources for their children.

Rules

Household rules, as they relate to academics, has been measured most often in previous literature as parental monitoring, rewards for excellent performance, and punishments for poor performance. Educational expectations, which can be transmitted in varying ways, are conveyed to students through these forms of household rules.

Parental monitoring includes both the supervision of and rules set for the amount of time spent on homework, extracurricular activities, and watching television. Literature reveals that monitoring benefits students' academic experiences through grades, academic motivation, and prevents delinquent behavior (Plunkett and Bamaca-

Gomez 2003; Plunkett et al. 2009; Romo and Falbo 1996). Conversely, high levels of 
parental monitoring can also have a negative impact on a child's academic performance. Ginsburg and Bronstein (1993) reported that a high level of involvement and supervision parents had over their child's homework was correlated with the child having poor grades. The authors suggest that high monitoring creates a dependency on outside forces to guide a student's academic behavior, and that the reliance on parents to direct their homework takes away their ability to take charge of the tasks on their own (Ginsburg and Bronstein 1993). It can also be reasoned that extreme parental monitoring might cause students to lose interest in school or confidence in their own academic ability because of this dependency, or as a rebellion against parental control.

Extrinsic rewards and punishments are given in order to sanction students on their performance in school. Ginsburg and Bronstein's (1993) study reported that extrinsic rewards and punishments were negatively related to a student's academic motivation (including self-confidence, effort, and interest) as well as achievement. Desire for rewards and fear of punishment can become the only incentives for students to do well in school, which might cause them to lose interest in learning. The authors suggest that it also hinders children from being able to evaluate their own understanding of academic content, which can lower self-confidence (Ginsburg and Bronstein 1993).

Monitoring is reflected in the parenting styles of Asian and Latino immigrant families. Literature depicts the values of many Latin American and Asian cultures as having strong family ties and putting the family community before the individual (Driscoll et al. 2008; Smart and Smart 1995). The family structure is hierarchical and parents enforce control over their children as a way to impose dominance and instill the 
value of family obligation. Thus, Latino and Asian parents may set rules for their children in order to exercise control.

\section{Latin American Immigrant Families}

The impact of parental monitoring is generally positive on Latin American immigrant students. In a study by Plunkett and Bamaca-Gomez (2003) on Mexican immigrant families, the authors found that students' perception of high parental engagement positively impacted their academic motivation. Parental engagement styles were defined as monitoring and ability to help with academics. Interestingly, the engagement types were not significantly related to students' educational aspirations (Plunkett and Bamaca-Gomez 2003). The authors suggested that parents' educational attainment might be related to this finding. Students who have higher educational aspirations than their parents' educational attainment may not want or need their parents' influence on academic-related activities (Plunkett and Bamaca-Gomez 2003).

A qualitative study based on observations and interviews with six Mexican American families, conducted by Delgado-Gaitin (1992), revealed that some Mexican parents rewarded or punished their children if the students' grades were high or low, respectively. Delgado-Gaitin (1992) also found that when children consistently performed poorly in school, rules concerning homework and time spent watching television were set by parents. In families where students did well in school, some parents set household rules while others did not.

Children from Mexican immigrant families are less likely to get involved in deviant behavior, such as drugs and crime, which take the student away from academics 
when they perceive a high level of rules from their parents (Plunkett and BamacaGomez 2003; Romo and Falbo 1996). Simultaneously, students are likely to engage in academic work when household rules are set. Parental monitoring is one form of parental engagement in Latin American immigrant households, and it has been shown to have a positive impact on children.

\section{East Asian Immigrant Families}

The parenting styles of Chinese American families include rigorous at-home teaching of academic material, and many parents even teach ahead of the curriculum being taught at school (Huntsinger and Jose 2009). Utilizing a formal method of teaching their children academic material at home, parents require their children to complete exercises and timed quizzes (Huntsinger and Jose 2009; Louie 2001). Chinese American parents who are not proficient in English do not spend much time instructing their children in literacy skills, but focus on the subjects of math and science (Huntsinger and Jose 2009). Parents often require their children to take extracurricular private lessons, such as computer science, a foreign language or a musical instrument (Louie 2001; Schneider and Lee 1990). The parental teaching style is a form of monitoring because these Chinese American parents control their children's extracurricular time and supervise them in academic-related tasks.

The at-home lessons are in addition to the strict amount of time that parents require their children to work on homework provided by the school. Many East Asian parents establish a set amount of time for their children to spend doing schoolwork and studying for class, and they closely monitor this time (Schneider and Lee 1990). Some 
parents also limit children's time with their friends and time watching television, to ensure that the students spend time working on academic activities (Schneider and Lee 1990). These thorough forms of parenting reflect the culture of the educational system in China. Stevenson, Lee, and Stigler (1986) compared U.S. schools with Chinese and Japanese schools and found that the East Asian schools spent more time on academic activities and placed a stronger emphasis on homework than U.S. schools. Overall, setting household rules is seen to be a major parenting style of East Asian families.

The rigorous and formal parenting style seen in Chinese-American families is partly in reaction to discrimination faced by Chinese immigrants and their Americanborn children (Louie 2001). Sue and Okazaki (1990) draw attention to the history of occupational discrimination towards Asians in the 1940s and post-WWII as manual laborers, which led Asian groups to obtain more education required for the new technological jobs. They suggest that because of this history, Asian-American groups hold education as an important value today. Education is also an important value to Chinese parents because they see it as a way to overcome discrimination faced today. To a Chinese-American parent, educational success can offset or diminish the discrimination (Louie 2001; Schneider and Lee 1990). Because of the history of discrimination and current discrimination in the U.S., Chinese-American parents are likely to hold high expectations for their children. In fact, Chen and Stevenson (1995) found that Asian American students perceived their parents to hold a higher expectation of student's grades than Caucasian-American, Chinese, and Japanese students.

Children of Chinese or Chinese-American parents can internalize the importance of education put upon them by their parents and strive to succeed in school (Louie 
2001). Schneider and Lee's (1990) interviews with East Asian students and parents revealed that many children understand the high expectations of academic achievement set forth by their parents, and shared that their parents were often not satisfied with grades of all As and Bs because they expected their children to earn all As. Excelling in school is following a rule set by their parents - it is fulfilling an expectation. For many children of Chinese immigrants, it also comes with awareness that their parents sacrificed much to allow them the opportunity for a good education in the United States (Louie 2001). Either way, high academic achievement for Chinese American students is a response to the values set in place by their parents, in the form of rules.

\section{South Asian Immigrant Families}

Indian immigrant parents set expectations for their daughters, as Raghavan, Harkness, and Super's (2010) study found. The Indian girls in the study were expected to be obedient to their parents. They were required to entertain household guests by serving food and drinks and conversing with them, and to agree to an arranged marriage set by their parents (Raghavan et al. 2010). Daily activities of these girls included bedtime grooming routines, household chores, and Hinduism classes, indicating that rules were set by their parents (Raghavan et al. 2010). In all facets of their lives, the Indian girls in Raghavan et al.'s (2010) study were monitored by their parents, and this centered on the Indian cultural value that favors family and collectivism over individualism (Markus and Kitayama 1991). The obedience and obligation to the family is instilled in the daughters through control by way of rules. 
Interaction

Communication about students' academics is another parenting style that relates to children's education. Previous literature supports two main types of parent-child academic communication: the transmission of the value of education, and discussions on specific areas of the student's academics, including grades, homework, and higher education plans. Parents who hold a high value of education frequently share their values with their children, hoping to steer them toward a successful academic future (Greene and Long 2011). Through conversations with their children, parents attempt to instill their educational beliefs and expectations on students, thus increasing a goaloriented mindset towards achievement and educational attainment (Kao 2004). While discussions may direct students to share their parents' beliefs, it does not always occur, but merely listening to parental values help students form their own academic goals and beliefs (Kao 2004). Parents also discuss specific aspects of a student's education in order to encourage and guide the student toward success in school (Louie 2001). This type of communication includes questions regarding a student's classes, schoolwork and grades, encouragement to study and complete homework, and conversations about the student's future in college and in taking standardized college-prep exams (Bowen, Bowen, and Ware 2002; Hao and Bonstead-Bruns 1998).

In general, open communication with parents helps children develop social skills used to manage people in the academic environment, such as teachers and peers (Kao 2004). It is also positively linked to a student's engagement in school, and lessens a child's involvement in school misbehavior (Bowen et al. 2002; Plunkett et al. 2009). 
Communication has been found to be positively related to academic achievement. Several studies have concluded that discussions regarding the value of education or specific aspects of a student's school experience lead to higher grades and test scores (Astone and McLanahan 1991; Baker and Stevenson 1986; Bowen et al. 2002; Kao 2004; Mau 1997; Pong, Hao, and Gardner 2005). It is important to note that there are some nuances in this link between communication and achievement. Kao (2004) found that discussion about college leads to higher grades but the impact gradually decreased, indicating that too much discussion lowers grades. One study found gender differences in parental engagement: academic advice from mothers was positively related to grades, while father's academic advice was not related to grades (Plunkett et. al 2009). The authors of this study suggested that mothers may spend more time or be more engaged than fathers in children's education, or that father's advice is less influential than father's behavior (Plunkett et. al 2009). There may also be racial differences, as one study found that communication between parents and students was not a significant predictor of achievement for both immigrant and native minority students; however, it significantly predicted achievement for native white students (Mau 1997).

\section{Latin American Immigrant Families}

Communication seems to be the engagement style most used by Hispanic parents. Kao's (2004) study that found a curvilinear pattern between communication and grades, as discussed above, discovered that a different pattern emerged when analyzing only Hispanic families. A linear pattern revealed that the amount of parent-child academic 
communication continually predicted higher grades and never reached a point where grades decreased (Kao 2004).

Sometimes communication is the most feasible way for Hispanic immigrant parents to be involved in their children's academic life. Lopez (2001), in his ethnographic study on immigrant families, learned from one Mexican family that a migrant lifestyle prevented the parents from being physically involved in their children's education. Instead, they communicated with their children about academics; they encouraged them to work hard and perform well, and their children proved very successful in their academic careers (Lopez 2001).

Communication is a tool frequently used by Hispanic immigrant parents to transmit values to their children (Delgado-Gaitin 1992). Delgado-Gaitin's (1992) qualitative study found that Mexican immigrant parents communicate their high value of education to their children, a value that stemmed from the parents' working-class background. The parents believed that their children would not have to suffer economically, as they did, if their children were successful in school. Other studies reflect the idea that education is an escape from potential economic hardships associated with a working-class lifestyle, and communication is the most common way for parents to transmit this belief (Brandt 1992; Lopez 2001).

\section{East Asian Immigrant Families}

The literature on academic communication between Asian parents and children is conflicting - some studies report that Asian parents communicate a great deal with their children (Louie 2001; Pong et al. 2005), while others conclude that Asian parents do not 
engage in this parenting style at all (Hao and Bonstead-Bruns 1998). Louie (2001) interviewed Chinese college students and reported that Chinese parents instill high expectations of academic success through communication. Parents encouraged their children to study and asked them about grades. This parenting style served as the vessel for Chinese parents to transmit the importance of education to their children (Louie 2001). Interestingly, Louie (2001) also found that working class Chinese parents had less communication with their children than Chinese parents in a higher economic class because work schedules caused them to have less time with their children. Hao and Bonstead-Bruns (1998) found in their quantitative study of native and immigrant youth that Korean immigrant parents frequently communicate with their children about education. Conversely, Chinese and Filipino immigrant parents do not often interact with their children when it comes to academics (Hao and Bonstead-Bruns 1998).

These differing findings may be due to the methods used in the different studies. Asian parents who engage in this parenting style share a high value of education and high academic expectations of their children. Questions asked in the different studies may have been similar, but different enough to result in differing conclusions. Specific questions regarding the frequency of discussions about schoolwork and college may have portrayed Asian parents as having low levels of academic communication.

\section{South Asian Immigrant Families}

Some South Asian mothers follow the parenting form of interaction. The study conducted by Ross-Sheriff and colleagues (2007) on South Asian ${ }^{1}$ Muslim immigrant

\footnotetext{
'The authors of this article did not specify the ethnic groups interviewed in the study, and the groups have been loosely defined as "South Asian."
} 
mothers revealed that mothering techniques on daughters consists of high levels of interaction. Mothers communicate appropriate behaviors and values to their daughters, with the hope that their daughters will develop a positive identity (Ross-Sheriff et al. 2007). Specifically related to education, mothers encourage their daughters to succeed in school because it can lead to self-sufficiency, an important value to the immigrant mothers.

Southeast Asian Immigrant Families

Previous work on parenting styles of Southeast Asian immigrants is scarce. One study on Cambodian students' academic experiences interviewed Cambodian-American youth. The study, conducted by Chhuon and colleagues (2010), indicated that Cambodian immigrant parents do not adhere to any specific parenting style. Some parents held high expectations for their children because of the potential financial benefits from attaining high educational status, while others held low expectations because older children (siblings of the respondents) had not achieved academic success (Chhuon et al. 2010). Results were vague in the specific ways that parents supported their children, but several students expressed that their parents had low levels of interaction with them; many parents did not communicate with their children about school subjects, grades, or homework. The overall conclusion suggested that Cambodian immigrant parents stayed outside of students' academic lives because they were unfamiliar with the education system and were low in English proficiency, which led them to feel unable to help (Chhuon et al. 2010). 


\section{Theoretical Framework}

As parents influence their children, they act out scripted roles based on cultural values and norms. For immigrant parents, they may learn the values and norms of more than one cultural system - their native country and the United States. This leaves them conflicted when engaging with their children in order to influence their academic experience. Role theory is useful in explaining this dissonance experienced by immigrant parents. Role theory has a broad range of conceptualizations and different theorists adhere to nuanced definitions of the theory (Biddle 1986). The specific variations of the theory include an underlying set of ideas and this basic description is used in this study.

A person plays a variety of roles throughout life, some of which might include parent, sibling, student, church deacon, or PTA president. Each role includes a set of behaviors to follow. The set of behaviors is defined by cultural values and norms of a society. Role theorists typically accept the functionalist definition of a norm as an expectation that is agreed upon by all society members - even if a theorist does not agree with structural functionalism as a whole (Biddle 1986). The expectations within a society dictate the behavior of individuals and set apart specific roles for members to follow.

Parents learn their expected behavior through interactions with others in the society (Mead 1934). By receiving positive and negative sanctions from other society members, parents learn the acceptable parental behavior and make adjustments to fit expectations. In learning acceptable academic engagement practices, parents might receive sanctions from fellow parents they encounter in school functions or extra- 
curricular activities, or from teachers and administrators that report to parents on a child's classroom behavior, academic performance, or parents' engagement with the child.

Role theory explains the learning of parental scripts for immigrants in a more complex fashion. Immigrant parents grow up and learn the culture of their native country and then immigrate to a country with a different culture. They know how to successfully play their role as parent from the cultural expectations of their native country, but may not be able to act out parenting roles as defined by U.S. cultural norms. Some may choose to act out the role of their native country and not learn the expected behavior of U.S. parents. Others may do the opposite, abandoning the prescribed role of their native country and embracing the cultural parental behavior of the U.S. Others, still, may attempt to blend the behavior of both cultural systems.

An example of the way that parental scripts are negotiated by immigrant parents can be found in the behavior of some Chinese immigrant parents. Many Chinese immigrant parents adhere to the authoritarian academic style found in Chinese schools by teaching ahead of the school's curriculum in the home and directing students to complete additional academic work (Huntsinger and Jose 2009). These parents continue to act out their parenting role learned in China, in which they promote academic achievement through diligent work out of school. This follows the Chinese value of uniformity in education - that all students can succeed if they study often and learn quickly (Stevenson, Lee, and Stigler 1986).

Parents act out their scripted role through the socialization of their children. The socialization process, like the prescribed behavior, is also set in a cultural context. 
Arnett (1995) describes two forms of socialization that are based on a cultural setting narrow and broad. Narrow socialization includes high levels of rules for children and expectations of obedience, while broad socialization focuses on individuality and independence (Arnett 1995). These forms of socialization are dependent on the cultural system of the society. The U.S. employs broad socialization, as parents teach their children the values and norms of the society by promoting independence and individuality. Some countries, such as China and Japan, utilize narrow socialization by teaching the society's culture through rules that encourage obedience and sameness. Immigrant parents from cultural systems with narrow socialization may struggle to follow the United States' broad socialization practices, as reflected above in the example of Chinese immigrant parents.

Parents influence their children through their engagement with them, and the forms of engagement rely upon the scripted roles set out for parents by the culture of a society. Portes and Rumbaut (2006) explain that children interpret the meanings behind their parents' influence practices based on their acculturation form. The acculturation process of an immigrant child impacts the relationship between the parents and child, which results in the ability for parents to influence the child. A child may learn and accept the culture of the society she lives in - the U.S. - while also carrying out the cultural traditions of the parents' native country. This is termed "selective acculturation," and an example of this is a child learning English while also continuing to speak his or his parents' native language (Portes and Rumbaut 2006).

Role theory, with the addition of broad and narrow socialization and mediated by acculturation process, is used to explain the academic engagement practices of 
immigrant parents as they connect to students' academic self-efficacy and educational attainment expectations in this study. Diagram 2, below, displays the theoretical model that incorporates the different ideas as they explain the relationship between parental engagement and academic experience.

Diagram 2: Theoretical Framework

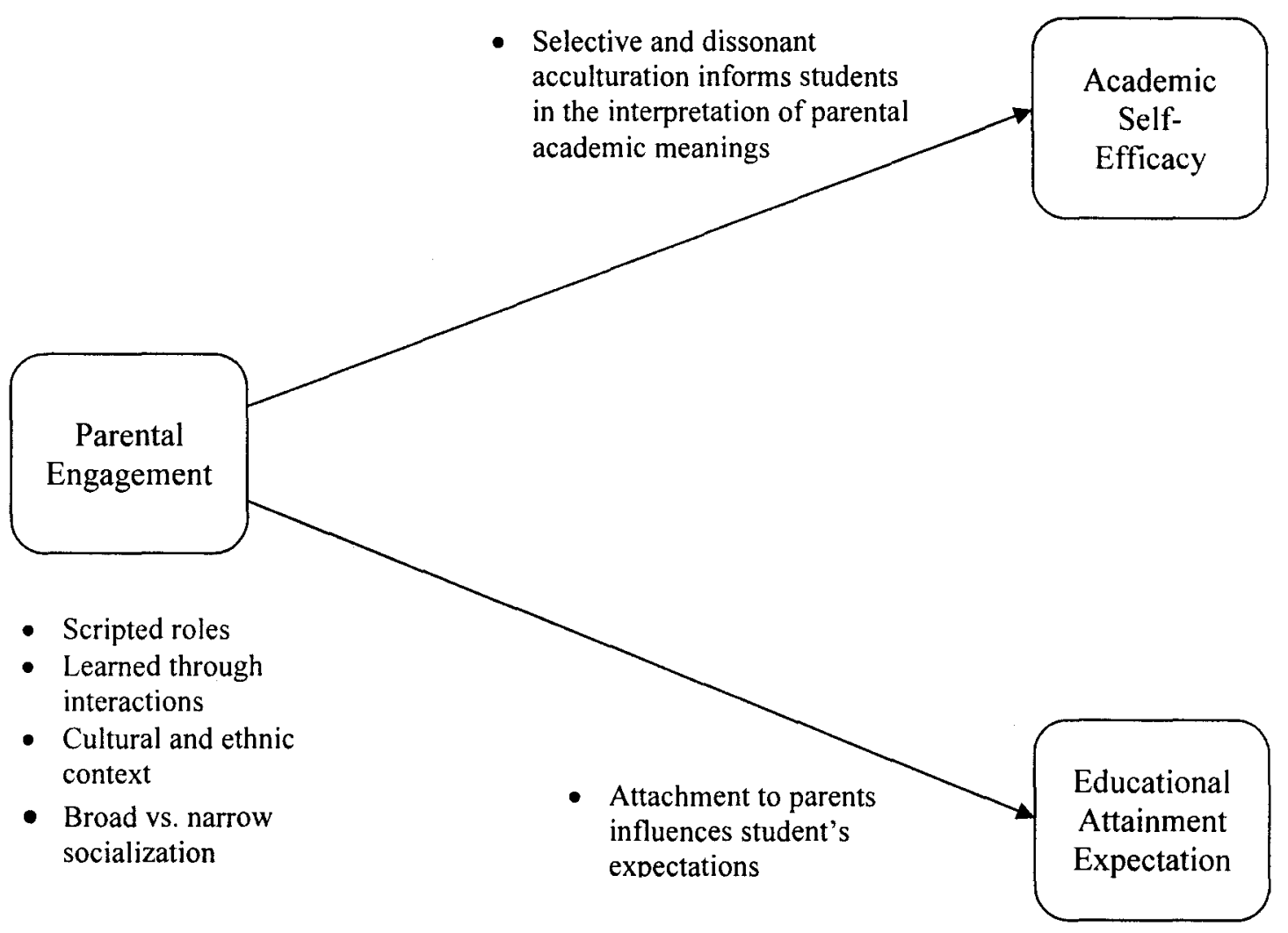

\section{Conclusion}

This study attempts to add to the growing literature on parental engagement and academic experience within immigrant families. Immigrant parents are shown to have varying styles of engagement, and I hope to develop the knowledge of these differences through quantitative analyses. Most studies that examine parental influence among 
immigrant minority groups have been qualitative, so a quantitative study will be useful in analyzing aggregates. 


\section{CHAPTER III}

\section{METHODS}

\section{Data Set}

Data were used from the base year of the Education Longitudinal Study of 2002 (ELS:2002). The longitudinal study followed approximately 15,000 high school sophomores through the completion of high school and into college and careers. Following the base year of 2002, the cohort was surveyed in 2004 and 2006, and will also be surveyed in 2012. In the base year, high school sophomores were surveyed on several topics, including attitude towards school, study habits, parental and peer involvement, and educational goals and expectations. Questionnaires were also completed by students' parents, math and English teachers, school principals, and heads of the school library center. Data were obtained using a stratified sampling method, in which schools were first selected and then students within each school were randomly selected. Private schools were sampled at a higher rate in order to provide a better comparison between public and private schools. Asian students were sampled at a higher rate than white, black, and Hispanic students to ensure an equal comparison between those groups. ELS:2002 is a nationally representative sample of children in the United States education system. 
The ELS:2002 data set was useful for my research because it provided a large sample of immigrant students and parents from a variety of cultural backgrounds. It also included measures of parental engagement styles and academic experiences of students. I decided to only use the base year of ELS:2002 because the parental engagement variables suited the interests of this study, and additional waves were not necessary to inform my research questions. My study utilized the student and parent survey data. The student survey provided information on educational experiences and perception of parental engagement. Data gained from the parent survey included demographic information of the parents. Specifically, the dependent variables of academic selfefficacy and educational attainment expectation were taken from the student survey, as well as the three main independent variables of in-home resources, household rules, and academic interaction. Control variables taken from the student survey consisted of student's sex, interest in school, teacher influence, peer influence, and hours spent in school-sponsored extra-curricular activities. Variables used from the parent survey were parents' educational attainment, family income, number of dependents, family composition, occupational status, number of years the parent has been living in the United States, and parent's native language.

\section{Sample}

Out of approximately 15,000 cases, 2,514 were selected as the sample of this study. The purpose was to examine second-generation immigrant high school students, so the sample was created by selecting cases based on three questions from the parent survey: "What is your relationship to the tenth grader?"; "Was your tenth grader's 
biological mother born in the United States, in Puerto Rico, or in another country or area?"; and "Was your tenth grader's biological father born in the United States, in Puerto Rico, or in another country or area?" The two questions asking about parents' birthplace prevented the sample to be created in one step. Cases in which the parent answered she is the student's biological mother and that she was born outside of the U.S. were first selected. There were 1,811 cases in this group. Cases in which the parent answered he is the student's biological father and that he was born outside of the U.S. were then selected. 703 cases made up this group. These two sub-samples were combined to create the sample used for the study. All parents included in the sample, then, were first generation immigrants born outside of the U.S. Using Portes and Zhou's definition of immigrant children, students in the sample were second generation immigrants who either moved to the United States before turning twelve years old or were born in the U.S. to at least one foreign-born parent (Portes and Zhou 1993).

It should be noted that the question on the parent survey asking respondents to indicate their relationship to the student included choices of birth, adoptive, step or foster mothers or fathers, extended family members, or non-parent guardians. Because the study was interested in the involvement of birth parents, those students whose birth parent did not answer the survey were eliminated from the analyses. While it is true that adoptive, step and foster parents often raise a child as the sole parent instead of the birth parents, the ELS:2002 study provided data on birth parents' home countries and it best served the study to exclude non-birth parents.

The sample included twenty different native languages, sorted into five broad language groups that indicate region of origin. For confidentiality reasons, ELS:2002 
recoded responses of parent's native language into a broad variable that was comprised of five native language groups sorted by region, as indicated earlier. ESL:2002 used two questions from the parent survey to create the native language group variable. One question asked if English was the respondent's native language. A subsequent question asked respondents whose native language was not English to indicate their native language from a list of nineteen languages. As there was no variable that explicitly revealed the parent's home country, parent's native language determined which ethnic group both parent and student belonged.

The frequencies of the native language groups are outlined below in Table 1. Out of my sample, approximately $25 \%$ of parents selected English as their native language, 38\% spoke Spanish, 3\% chose a non-Spanish European language (including Italian, French, German, Greek, Polish, and Portugese), 7\% selected Western or Southern Asian (Arabic, Farsi, Urdu, Hindi, Tamil or other Indian subcontinent language) as their native language, and $22.5 \%$ spoke a Pacific or Southeastern Asian language (Japanese, a Chinese language, Korean, a Filipino language, Vietnamese, Cambodian, or another Southeast Asian language). The native language groups with the largest number of respondents were Spanish, English, and Pacific or Southeastern Asian language. The native language group, "Other," was removed from the set of language groups because there was no way to identify the region of origin for those parents. Thus, the data on those cases were deemed not useful for this study. There were 162 parents in the sample who reported that they speak another language. 
Table 1: Frequency and Percentage of Parent's Native Language

\begin{tabular}{lccc}
\hline \hline & Mother & Father & Total \\
\hline English & $415(27.5)$ & $125(21.74)$ & $540(24.73)$ \\
Spanish & $638(42.3)$ & $183(31.83)$ & $821(37.59)$ \\
Other European language & $59(3.91)$ & $15(2.61)$ & $74(3.39)$ \\
West/South Asian language & $87(5.77)$ & $70(12.17)$ & $157(7.19)$ \\
Pacific Asian/Southeast Asian language & $310(20.54)$ & $182(31.65)$ & $492(22.53)$ \\
\hline & $1509(100 \%)$ & $575(100 \%)$ & $2184(100 \%)$ \\
\hline \hline
\end{tabular}

Missing data limited the number of cases in the native language variable -189 mothers and 79 fathers did not provide their native language. From exploring this group of parents, many failed to answer questions throughout the entire survey. From the question asking if English was their native language, all but one father responded that it is not their native language. Approximately $75 \%$ reported Asian as their race and the mean family income fell between 25 and 50 thousand dollars. Almost half of the mothers and $30 \%$ of the fathers in the group did not finish high school. Overall, these parents seem to have low socioeconomic status, be part of a racial minority group, and most likely have low English fluency.

\section{Variables}

Dependent Variables

The variable of academic self-efficacy derived from a set of 22 questions regarding a student's confidence in school-related topics. Measures in the set asked students to designate how often each item applied to them. Students could answer, "Almost never," "Sometimes," "Often" and "Almost Always." A factor analysis, using orthogonal rotation, was conducted and three forms of academic self-efficacy were 
revealed: Study, Math, and English. Study items indicated reasons why the student studies and the effort put into studying. The set of Math items specified the student's confidence in performing well in math class; likewise, the English items reported on the student's confidence in performing well in English class. A complete list of the 15 measures can be found in Table $\mathrm{A}$ in the Appendix.

The items used to create this variable were measured in the same direction, so recoding was not necessary. When totaled, each of the scores for the three variables ranged from 0 to 15 . The internal consistency coefficients of the sets of variables used to measure academic self-efficacy were .869 for Study, .929 for Math, and .914 for English, indicating strong measures of reliability.

The student's educational attainment expectation was measured with one variable. Students were asked how far in school they think they will get, with the choices of "Less than high school graduation," "High school graduation of GED only," "Attend or complete a 2-year school course in a community or vocational school," "Attend college, but not complete a 4-year degree," "Graduate from college," "Obtain a Master's degree or equivalent," "Obtain a Ph.D., M.D., or other advanced degree" and "Don't know." This ordinal variable was coded 1 to 7 , and a higher number indicated that a student expected to have more schooling.

\section{Independent Variables}

The parental engagement variables were each calculated using composite scores of variable groups. The complete set of final items used to measure the parental engagement variables are on Table $A$ in the Appendix. The variable measuring the 
amount of resources available at home was calculated by totaling the number of resource types that students selected. A survey question asked students to check "Have" for each type of resource available in their home. Based on previous literature, four types of inhome resources were used in the study. Items included a computer, access to the internet, more than fifty books, and the student has her own room. The range was 0 to 4 , with a higher score indicating more in-home academic resources than a lower score.

The academic rules variable was created from a set of items on the questionnaire - scores from a set of variables were summed to create one composite variable.

Selecting from the responses of "Never," "Rarely," "Sometimes" and "Often," students reported the frequency that they perceived their parents to set rules and check homework. After performing a factor analysis (using orthogonal rotation) on the set of variables, four variables were found to be adequate measures of parental rules. These items included parents checking if their homework has been completed, limiting time watching television and playing video games, limiting time spent with friends on school nights, and requiring chores to be carried out. With a range of scores from 0 to 12 , a higher score indicated that students believed to have more rules set by their parents than those with lower scores.

To formulate the parental interaction variable, a factor analysis was performed, using orthogonal rotation, on a set of variables that asked students to measure their perception of time spent talking with their parents on academic-related topics. Students were asked to choose from the frequencies of "Never," "Sometimes," and "Often." The discussion topics included choosing school classes, activities the student is interested in, class curriculum, grades, college preparation tests, going to college, news events and 
things that are troubling the student. The sum of the final set of eight variables was 16 , so the range of available scores was 0 to 16 . Therefore, a higher score indicated that students perceived more academic communication with their parents than a lower score. The internal consistency coefficients (measured by Cronbach's alphas) for each composite variable score were .575 for resources, .856 for interaction, and .628 for rules.

\section{Control Variables}

Control variables were introduced in order to better isolate the correlation of parental engagement on student academic self-efficacy and educational attainment expectation. Additional variables in the study included questions from both the student and the parent survey. From the student survey, variables included the student's interest in school, weekly hours the student spent in school-sponsored extra-curricular activities, teacher influence, peer influence, and the student's sex. From the parent survey, controls consisted of the number of dependents that the parent(s) provided for, family income, number of years the parent has been in the U.S., the parent's educational attainment, occupational status, and the family composition.

A student's interest in school came from the question asking how much the student liked school. The student could choose between "Not at all," "Somewhat," or "A great deal." The question reporting the hours spent on school-sponsored extracurricular activities was open-ended and students were asked to fill in the blank. Extracurricular activities have been found to mediate the effect of attainment expectations on college attendance (Beal and Crockett 2010). The student's sex was included because literature has shown that immigrant girls have higher academic motivation and 
educational attainment than boys (Hao and Bonstead-Bruns 1998; Plunkett and BamacaGomez 2003). The dichotomous variable was recoded into a dummy variable with male measured as " 1 ".

Teacher and peer influence were used as controls because theoretical and empirical literature shows that teachers and peers play important roles in a student's academic life and decision-making ability (Colvin and Schlosser 1997; Eccles et al. 1998; Schlosser 1992; Schunk and Carbonari 1984). Thus, controlling for these factors allowed the relationship between parents and students to be isolated. The teacher influence variable derived from four items in which the student was asked to respond with, "Strongly agree," "Agree," "Disagree," or "Strongly disagree." The items reflected the student's perception of her teacher: "The teaching is good"; "Teachers are interested in students"; "When I work hard on schoolwork, my teachers praise my effort"; "In class I often feel 'put down' by my teachers". Three out of four variables were recoded so the direction of the responses would be in agreement, and the scores were totaled. The range of scores is 0 to 4 , with a higher score indicating a higher measure of teacher influence.

Peer influence was measured by averaging the scores from three questions from the student questionnaire. The student was asked to think about his or her three closest friends and then respond to this question: "How important is getting good grades to this friend?" The student could answer, "Not at all important," "Somewhat important," or "Very important". The composite score calculated from these questions measured the level of influence that a student's closest peers have on the student. 
The number of dependents the parent financially provides for may reflect the parent's potential ability (or inability) to engage with the student. Many dependents may indicate that the parent has limited time and money to spend with the child because the parent must work long hours or hold multiple jobs in order to provide for everyone. The open-ended question asked, "Altogether, how many people are dependent upon you or your spouse/partner? Count everyone (besides yourself and your spouse/partner) who receives one-half or more of their financial support from you or your spouse/partner. Include individuals not living with you and your spouse/partner." This number of dependents could include children in or out of the home, older relatives such as parents who live in or out of the home, and any other relatives or non-relatives that may or may not live in the parent's home but relies on the parent for financial support. This variable captured an inclusive list of people who may be counted as dependents, and was chosen over other available variables ("number of children" or "number of people in household" as examples).

Family income is often linked to educational expectations and achievement, as well as in-home resources, and served as a vital control variable in this study (DelgadoGaitin 1992). The parent questionnaire asked the respondent to share the total family income from all sources in the previous year, having the parent choose from an ordinal list of income ranges. The number of years the parent has been in the U.S. was added as a control because research suggests that parenting styles may shift as immigrant parents become more acculturated to U.S. culture and the education system (Driscoll et al. 2008; Fong 1997). Two separate open-ended questions were used to capture the number of years each parent has lived in the U.S.: "How many years ago did [student's birth 
mother] come to the United States to stay?" and "How many years ago did [student's birth father] come to the United States to stay?"

Parents' occupation was not included as a control because immigrants often experience downward mobility when moving to the United States and educational attainment is more accurate in portraying an immigrant's occupational worth (Feliciano 2005). Many immigrants are highly educated in their home countries but, upon their migration to the U.S., cannot obtain a job that reflects their education level. Research has also shown a positive relationship between parental educational attainment level and a child's educational attainment expectation and student academic engagement (Hao and Bonstead-Bruns 1998; Plunkett et al 2009), so it was beneficial for this study to examine the effects of parental engagement while holding parents' educational attainment level constant.

However, literature has revealed that parental engagement with their children in academics can vary with the parent's occupation (Delgado-Gaitin 1992; Kao 2004; Lopez 2001). An immigrant parent's long work hours or atypical shift schedule may impact the time the parent can spend with his children. Therefore, occupational status was added as a control variable, measured as "Full-time (35 hours or more)," "Part-time (less than 35 hours)," or "Not at all".

The family composition of each respondent was constructed by ELS:2002 using three questions from the parent survey and was available in the data set. This variable was intended to distinguish the different types of parental arrangements. The three questions used to create this survey included, "What is your relationship to the tenth grader named on the front cover?"; "What is your spouse/partner's relationship to the 
tenth grader named on the front cover?"; and "How much of the time does the tenth grader named on the front cover live with you?" The responses revealed that students lived with both parents, one birth parent and the parent's spouse/partner, single parent, or did not live with parent respondent more than half of the time.

\section{Descriptives}

Students were above average in their academic self-efficacy for all three measures. The mean response for Study was 9.45 with a standard deviation of 3.63 . Math scored an average of approximately 8 with a standard deviation of 4.06 , and English had an average score of 8.70 with a standard deviation of 3.73. These descriptives are displayed below in Table 2 .

Table 2: Descriptives for Academic Self-efficacy Variables: Study, Math, and English

\begin{tabular}{|c|c|c|c|c|}
\hline & & $\begin{array}{l}\text { Study } \\
(0-15)\end{array}$ & $\begin{array}{l}\text { Math } \\
(0-15)\end{array}$ & $\begin{array}{c}\text { English } \\
(0-15)\end{array}$ \\
\hline \multirow[t]{2}{*}{$\mathrm{N}$} & Valid & 1555 & 1575 & 1617 \\
\hline & Missing & 959 & 939 & 897 \\
\hline \multicolumn{2}{|c|}{ Mean } & 9.45 & 8.24 & 8.70 \\
\hline \multicolumn{2}{|c|}{ Median } & 10 & 8 & 9 \\
\hline \multicolumn{2}{|c|}{ Std. Deviation } & 3.63 & 4.06 & 3.73 \\
\hline
\end{tabular}

Most students believed they would, at the minimum, graduate from a four-year college. $37 \%$ of students expected to graduate from college, while $48 \%$ expected to obtain an advanced degree. Only $6.3 \%$ of the respondents expected high school to be their final education level, while $8.5 \%$ predicted they would attend some college. See Table 3 below. 
Table 3: Frequency and Percentage for Educational Attainment Expectation

\begin{tabular}{lcc}
\hline \hline & Frequency & Percent \\
\hline Less than high school graduation & 23 & 1.1 \\
High school graduate & 112 & 5.2 \\
Some college & 183 & 8.5 \\
College graduate & 800 & 37.2 \\
Advanced degree & 1035 & 48.1 \\
\hline Total & 2153 & $100 \%$ \\
\hline
\end{tabular}

Table 4, below, displays the numerical descriptives for the parental engagement variables. Out of four types of resources in a student's home, the mean number was approximately three with a standard deviation of 1.05 . Almost half of the students responded that there are no more than three types of resources present in their homes, which means that approximately half of the students have all four types of resources. The mean response for parental rules was approximately 7 with a standard deviation of 2.84 , and the most common score was 8 . This indicated that students believe their parents set a moderately high amount of rules. The mean score of the parental interaction variable was 7.18 with a standard deviation of 2.84 , indicating that, on average, a student perceives to have a moderate amount of academic communication with parents. 
Table 4: Descriptives for Parental Engagement Variables: Resources, Interaction, and Rules

\begin{tabular}{|c|c|c|c|c|}
\hline & & $\begin{array}{c}\text { Resources } \\
(0-4)\end{array}$ & $\begin{array}{l}\text { Rules } \\
(0-12)\end{array}$ & $\begin{array}{c}\text { Interaction } \\
(0-16)\end{array}$ \\
\hline \multirow[t]{2}{*}{$\mathrm{N}$} & Valid & 2053 & 1916 & 1851 \\
\hline & Missing & 461 & 598 & 663 \\
\hline \multicolumn{2}{|c|}{ Mean } & 3.21 & 7.18 & 7.18 \\
\hline \multicolumn{2}{|c|}{ Median } & 4.00 & 7.00 & 7.00 \\
\hline \multicolumn{2}{|c|}{ Std. Deviation } & 1.05 & 2.84 & 2.84 \\
\hline
\end{tabular}

The descriptive numbers for the control variables can be found in Tables B through $\mathrm{H}$ in the Appendix. When asked how much one likes school, over half of the students answered that they "Somewhat" like school. 30\% of students like school "A great deal," while only $7.5 \%$ answered "Not at all." The students engaged in an average of 3.5 hours of weekly extra-curricular activities, with a standard deviation of approximately 5 . Students perceived that their teachers positively influenced them, with the mean response at 11.86 , with a standard deviation of 1.92. Many students reported that their closest friends believed that good grades were somewhat important, with a mean score of .48 and a standard deviation of .50. The sex of the students was divided evenly, with $48 \%$ male and $52 \%$ female. On average, the number of dependents in which the parent(s) provided for was three people. Over half of the respondents reported a family income of $\$ 50,000$ or less. Tables B through D in the Appendix has these numbers.

The parents of the students in the study have been in the United States for an average of 19 years. The number of years in the U.S. ranged from less than a year to 50 years, with $80 \%$ of mothers and $78.5 \%$ of fathers arriving in the past 25 years. More 
fathers hold full-time jobs than mothers do, while more mothers than fathers do not have a job. The parents hold a full-time job more often than a part-time job or no job at all. See tables $\mathrm{E}$ and $\mathrm{F}$ in the Appendix for these numbers.

The majority of the mothers in the sample attended no more than two years of college, and $29 \%$ did not finish high school. Likewise, over half of the fathers attended no more than two years of college. However, $40 \%$ of fathers hold a college or advanced degree, while only $28 \%$ of mothers hold the same. The family composition for the majority of respondents was made up of both biological parents $(71 \%)$. Single parent households are the next highest type of household represented, followed by the parent and parent's significant other. Less than $1 \%$ of the parent respondents live with their child less than half of the time. Tables $\mathrm{G}$ and $\mathrm{H}$ in the Appendix reflect these numbers.

\section{Analysis Procedure}

Analysis of Covariance (ANCOVA) and Multivariate Analysis of Covariance (MANCOVA) statistical analyses were employed in this study. ANCOVA compares the adjusted means of an independent variable on a dependent variable, while controlling for covariates. MANCOVA analyzes the same, but on multiple dependent variables instead of one. In these analyses, the means of each group of an independent variable on a dependent variable are adjusted by the means of the covariates in the model. The covariates are included in order to help decrease the variation in the dependent variables that may be attributed to outside variables. They help isolate an independent variable as a predictor of the dependent variable. 
This method was useful for this study because it allows for comparison between native language groups while studying the impact of the parental engagement variables on the dependent variables. The purpose of this study was to explore the impact that parental engagement has on academic self-efficacy and educational attainment expectation of the sample of immigrant families, and to observe differences in the impact of parental engagement on the academic experiences between native language groups. Thus, all three research questions were explored using the same method.

First, ANOVAs were run to compare the raw means of each independent variable on each dependent variable and understand the basic relationship between the variables. Then, to analyze the impact of parental engagement on academic self-efficacy, MANCOVAs were run with each engagement variable as fixed factors on the three measures of efficacy (Study, Math, and English), and control variables were added to the model. I ran the three measures of efficacy together as dependent variables in the MANCOVAs but analyzed them separately. Control variables were added in two groups: family characteristics and student characteristics. Family characteristics were those variables that derived from the parent survey: native language, income, mother and father educational attainment, number of years mother and father have been in the U.S., number of dependents, and family composition. Student characteristics included variables that came from the student questionnaire: male, teacher and peer influence, extra-curricular activities, and interest in school. Family characteristics were included with the parental engagement independent variable as Model 1, and the addition of student characteristics was Model 2. In a third model, interactions between the parental engagement variable and a number of control variables were added. Interactions were 
conducted on the second models to observe the way that the impact of parental engagement styles on efficacy changes with different control variables. The relationships between rules and all three measures of efficacy were complex, so the MANCOVAs performed for rules on efficacy included different variables than were performed for resources and interaction. This will be explained in the Results chapter.

When a parental engagement variable was found to be a significant predictor of a dependent variable, pairwise comparisons were analyzed in a post hoc test. The Bonferroni method was utilized to correct the error rate of the multiple comparisons. It held the error rate of each comparison to the prescribed alpha error rate.

The impact of parental engagement on educational attainment expectation was explored using a similar method to self-efficacy, but ANCOVA analyses were used instead of MANCOVA because attainment expectation was measured using one variable. The impact of engagement on attainment expectation was controlled by covariates, added in different models as described with the MANCOVAs. Engagement and family characteristics were analyzed in Model 1, student characteristics were added to create Model 2, and Model 3 included interactions between engagement and various controls. Bonferroni pairwise comparisons were again used to interpret the significant findings.

The impact of parental engagement on the dependent variables was compared between native language groups using post hoc tests of Bonferroni pairwise comparisons in (M)ANCOVA analyses. These comparisons were conducted first without covariates in order to understand the basic differences in the groups, and to determine if the comparisons were significant at the basic level. Then, they were compared with the full 
set of covariates (Model 2) of each (M)ANCOVA to find out the differences between each native language when controlled for the full set of covariates. 


\title{
CHAPTER IV
}

\author{
RESULTS
}

\section{Introduction}

This chapter describes the findings of the statistical procedures. First, the research question addressing the impact of parental engagement on academic selfefficacy will be discussed, followed by the question addressing the impact of parental engagement on educational attainment expectation. Finally, the research question on native language comparisons will be addressed - I will discuss whether or not the impact of parental engagement on the dependent variables differs between native language group.

To remind the audience of the hypotheses presented at the beginning of this study, I predicted that parental engagement has a positive impact on academic self-efficacy and educational attainment expectation. I expected that the measures of parental engagement - resources, interaction, and rules - leads to a higher academic self-efficacy and educational attainment expectation for a student. Related to the native language comparisons, I expected to find that the way resources, interaction, and rules impact a student's academic self-efficacy and educational attainment expectation will differ between native language groups. Specifically, I predicted that the impact of resources and rules on efficacy and expectation is greater for East Asian families than the other 
groups, and that the impact of interaction is greater for Spanish families than other groups.

\section{Academic Self-Efficacy}

Tables $\mathrm{J}$ through $\mathrm{L}$ in the Appendix display the numerical findings of the impact of the parental engagement variables on academic self-efficacy. Each table reports the results of each parental engagement variable: Resources, Rules, and Interaction. The tables include F-statistics of the MANCOVA results, and are divided into three models. The first model shows the parental engagement variable with family characteristics, the second model contains both family and student characteristics, and the third model

shows interactions that were added to Model 2. Each interaction was added to Model 2 individually and removed before adding a different interaction so that the interactions would not impact one another. Only significant interactions were recorded in the tables.

Before MANCOVAs were run, ANOVA analyses compared the raw means of each parental engagement variable and academic self-efficacy in order to understand the basic relationship between the engagement variables and efficacy without covariates. Table I in the Appendix displays these numbers. The mean differences for resources and interaction were statistically significant with Study, Math, and English efficacy. Significant differences were found between rules and Study and English efficacy. The raw means of rules and Math efficacy were not found to be significantly different, so it was interesting to explore this relationship further using MANCOVAs. 


\section{Resources}

Family characteristics were added as covariates in the first model with resources. By observing the statistically significant Wilk's Lambda $(p=.009)$, the group of variables in this model proved to be a good fit for predicting academic self-efficacy. The adjusted $r^{2}$ reported the proportion of variation in each measure of efficacy due to the variation of resources and family characteristics. The adjusted $r^{2}$ for efficacy were .032 for Study efficacy, .046 for Math efficacy, and .051 for English efficacy. When comparing the main effects of Model 1, resources was a significant predictor of Study efficacy $(p=.046)$, Math efficacy $(p=.007)$, and English efficacy $(p=.040)$, when adjusted for family characteristics. See Table $\mathrm{J}$ in the Appendix for these figures.

When student characteristics were added in Model 2, the group of variables proved to be a good fit for predicting efficacy (Wilk's Lambda $p=.002$ ). The adjusted $r^{2}$ is .149 for Study efficacy, .139 for Math efficacy, and .115 for English efficacy, and these values explain the proportion of variation in Study, Math, and English efficacy due to the variation of resources, family, and student characteristics. The impact of resources on Study and Math efficacy remain significant $(p=.029$ and .000 , but English efficacy becomes not significant $(p=.121)$. Table $J$ in the Appendix displays these values. Because resources was not a significant predictor of English efficacy in the second model, further examination of the data was not conducted for this measure of efficacy.

Pairwise comparisons reported differences within the adjusted means of resources when measuring Study and Math efficacy in the second model. Students whose homes have four types of resources have a significantly higher Math efficacy than students who 
have zero, one, or two resource types. Pairwise comparisons revealed no significant differences between resource types for Study efficacy. Interactions revealed that the impact of resources on Study efficacy increases by .039 unit with every increase in father's attainment level.

Rules

The first model of rules on efficacy included the following family characteristics: native language, parent's occupational status, income, mother and father's educational attainment, family composition, and number of dependents. Based on preliminary analyses, the control variables of years the student's mother and father have been in the U.S. were not included in Model 1 because the model became not significant when these two variables were added.

Wilk's Lambda indicated that the group of variables used in Model 1 fit well together as predictors of efficacy $(p=.016)$. The adjusted $r^{2}$ is .041 for Study efficacy, .034 for Math efficacy, and .042 for English efficacy. These signify the proportion of variation in Study, Math, and English efficacy due to the variation of rules and some family characteristics. Within the model, rules was a significant predictor of Study efficacy $(p=.001)$, when controlling for some family characteristics. Rules was not a significant predictor of Math and English efficacy ( $p=.926$ and .192). Table K in the Appendix has these numbers.

The student characteristics of male and hours of extra-curricular activities were added to the model because they were the only student control variables that could be added without making the model become not significant. The group of variables in 
Model 2 was a good fit to explain academic self-efficacy (Wilk's Lambda $p=.047$ ). The adjusted $r^{2}$ is .055 for Study efficacy, .069 for Math efficacy, and .051 for English efficacy, reporting the proportion of variation in Study, Math, and English efficacy due to the variation of rules, some family, and some student characteristics.

Individually, rules was a significant predictor of Study efficacy $(p=.001)$ and was the only measure of efficacy to be significant. Rules was not a significant predictor of Math and English efficacy ( $p=.981$ and .454$)$. Pairwise comparisons found no significant differences to explain the relationship between rules and Study efficacy. When measuring Study efficacy, none of the interactions added to Model 2 were significant. These figures are found in Table $\mathrm{K}$ in the Appendix.

Interaction

Family characteristics were evaluated in Model 1 . The group of variables in the model were a good fit in explaining academic self-efficacy (Wilk's Lambda $p=.000$ ). The adjusted $r^{2}$ was .110 for Study efficacy, .040 for Math efficacy, and .084 for English efficacy, reporting the proportion of variation in Study, Math, and English efficacy due to the variation of interaction and family characteristics. Interaction was found to be a significant predictor of Study and English efficacy ( $p=.000$ for both), but it does not significantly predict Math efficacy $(p=.070)$. See Table L in the Appendix for these numbers.

In Model 2, student characteristics were added. The group of variables in the model was a good fit for explaining academic self-efficacy (Wilk's Lambda $p=.000$ ). The adjusted $r^{2}$ values explained the proportion of variation in Study, Math, and English 
efficacy due to the variation of interaction, family, and student characteristics. The adjusted $r^{2}$ is .207 for Study efficacy, .126 for Math efficacy, and .143 for English efficacy. Interaction remained a significant predictor of Study and English efficacy $(p=.000$ and .012$)$. Interaction also continued to not significantly predict Math efficacy ( $p=.164)$. Table $\mathrm{L}$ in the Appendix has these values.

Differences within interaction were compared in order to explore the relationships between interaction and Study and English efficacy. Students who have a high level of academic interaction with their parents have a significantly higher Study self-efficacy than students with a mid-low and mid level of parental interaction. No significant differences were found within the levels of interaction on English efficacy. Interactions revealed that the impact of interaction on Study efficacy increases by .076 unit with every unit increase in family income. None of the interactions included in the analysis of English efficacy were significant.

\section{General Observations}

When examining Tables $\mathrm{J}$ through $\mathrm{L}$ in the Appendix, some features of the relationship between parental engagement and academic self-efficacy stand out above others. Looking at Tables $\mathrm{J}$ and $\mathrm{K}$, only one family characteristic control variable is a significant predictor of Study efficacy. The number of dependents predicts Study efficacy when it's controlled by resources in Model 1, and rules in Models 1 and 2 . Many student characteristics are significant predictors of Study efficacy, but male is never significant with any of the parental engagement variables, as seen in Tables $\mathbf{J}$ through K. 
Three family characteristics are significant predictors of Math efficacy - native language, income, and father's educational attainment, and these appear only when rules and interaction are the parental engagement variables. Most of the student characteristics are significant predictors of Math efficacy, with extra-curricular activities only significant when related to rules. Tables $\mathrm{J}$ through $\mathrm{K}$ reflect these results.

According to Tables $\mathrm{J}$ through $\mathrm{K}$, few family characteristics are significant predictors of English efficacy when resources and rules were the parental engagement variables - native language, mother's educational attainment, father's educational attainment, and dependents. The family characteristics were significant in Model 1; native language is the only family characteristic that is found to be significant in Model 2. Most of the student characteristics are significant predictors of English efficacy. Male is only significant when related to rules. It is also interesting to note that the adjusted $r^{2}$ value increases between Model 1 and 2 each time. The addition of the student characteristics increases the proportion of variation in academic self-efficacy due to the inclusion of the full set of controls.

\section{Educational Attainment Expectation}

The relationship of parental engagement and educational attainment expectation is numerically shown in Table $\mathrm{M}$ in the Appendix. It contains the F-statistics of the individual variable findings from the ANCOVA analyses. The table is divided into three models. The parental engagement variable and family characteristic controls composed Model 1 and student characteristics were added to become Model 2. Model 3 included interactions that were added to the second model. Each interaction was added to Model 
2 separately so they would not impact each other. The significant interactions are seen in the table under Model 3.

ANOVA analyses were first performed with each parental engagement variable and educational attainment expectation in order to observe the basic relationship between the independent and dependent variables without controls. See Table I in the Appendix for these numbers. The mean differences for each parental engagement variable were significant for expectation. ANCOVAs will further reveal the relationships between these variables.

Resources

Model 1 included resources and family characteristics. The adjusted $r^{2}$ of this model was .155 , which is the proportion of variation in expectation due to the variation of resources and family characteristics. In this model, resources is a significant predictor of expectation $(p=.000)$. Student characteristics were added in Model 2, and the adjusted $r^{2}$ was .252 . This tells us the proportion of variation in expectation due to the variation of resources, family, and student characteristics. Resources is again found to be a significant predictor of expectation $(p=.000)$. These values are found in Table M in the Appendix.

In Model 2, pairwise comparisons within resources found that students who have all four types of in-home resources have a higher educational attainment expectation than students with zero or one type of resources. Interactions revealed further interpretation of the relationship between resources and attainment expectation. The impact of resources on expectation is different per parent's native language. This area 
will be discussed later in the chapter. The impact of resources on expectation decreases .006 unit when income increases each unit, and it also decreases .032 unit for each additional dependent the parent supports. The impact of resources on expectation is .403 unit greater for female students than male students. Finally, the impact of resources on expectation increases .059 unit as mother's educational attainment level increases per unit.

Rules

The impact of rules on attainment expectation was similar to that of resources. Family characteristics and rules were included in the ANCOVA analysis as Model 1. The adjusted $r^{2}$ of this model was .167 , which is the proportion of variation in expectation due to the variation of rules and family characteristics. Individually, rules significantly predicts expectation $(p=.000)$. When student characteristics are added in the second model, rules remains significant $(p=.000)$. The $r^{2}$ of Model 2 is .258 , indicating the proportion of variation in expectation due to the variation of rules, family, and student characteristics. Table $\mathrm{M}$ in the Appendix displays these figures. Overall, rules is a significant predictor of educational attainment expectation.

When analyzing pairwise comparisons within rules, students whose perceived level of rules is greater than one have a significantly higher attainment expectation than students whose have no perceived rules. Interactions found that the impact of rules on expectation decreases .002 unit for every additional year that the father has been in the U.S. The decrease is small, but it does report the negative change in impact. 
Interaction

The analysis of interaction and family characteristics on expectation, in Model 1, reveals that interaction is a significant predictor of expectation when controlling for family characteristics $(p=.000)$. The $r^{2}$ of this model is .184 , which describes the proportion of variation in expectation due to the variation of interaction and family characteristics. When adding student characteristics, the $r^{2}$ of the model is .249 , indicating the variation in expectation due to the variation of interaction, family, and student characteristics. Interaction remains a significant predictor of expectation $(p=.000)$. Table $\mathrm{M}$ in the Appendix has these numbers.

When examining educational attainment expectation adjusted by all control variables (Model 2), students who reported having a mid and high level of academic parental interaction have a significantly higher expectation than students who reported no parental interaction. This suggests that a higher level of interaction leads to a higher expectation than having no interaction with parents. Interactions inform us of the relationship between interaction and expectation in more depth. Findings report that the impact of interaction on expectation is different for each native language, and this will be discussed later in the chapter. The impact of interaction on expectation is less when the student's parent has no job or a part-time job than if the parent holds a full-time job. The impact of interaction on expectation decreases when the parental arrangement does not include both biological parents. The impact of interaction on expectation increases .003 unit as the mother's years in the U.S. increases, and also increases .001 unit the longer the father has been in the U.S. Finally, the impact of interaction on expectation increases .058 unit as mother's educational attainment level increases per unit. 


\section{General Observations}

Looking across Table $\mathrm{M}$ in the Appendix, the family characteristics of native language and mother's educational attainment are found to be significant predictors of expectation with each parental engagement variable and for every model. Parent's occupational status is also a significant predictor in Model 2 for every parental engagement variable, and is significant in Model 1 with interaction. The student characteristic of teacher influence is a significant predictor of expectation when controlling for resources, but is not significant when controlling for rules or interaction. Every other student characteristic significantly predicts expectation when relating to all of the parental engagement variables.

The adjusted $r^{2}$ change from Models 1 to 2 was positive for each parental engagement variable. The adjusted $r^{2}$ value increases between Models 1 and 2 each time. This explains that the addition of the student characteristics increases the proportion of variation in educational attainment expectation due to the parental engagement variable and all of the controls.

\section{Native Language Comparisons}

Differences between native language groups were evaluated as part of two different models - alone with the parental engagement variable and then with the addition of the full set of covariates. Tables $\mathrm{N}$ through $\mathrm{Q}$ in the Appendix display the differences in adjusted means between each native language group when the impact of the parental engagement variables on the dependent variables was assessed. The adjusted mean of the group placed in the columns is subtracted from the adjusted mean 
of the group in the rows. Model 1 indicated that the native language groups were compared when the variable of native language served as the only control for the parental engagement variables. Model 2 included the parental engagement variable with the full set of family and student characteristics as covariates. When rules is the parental engagement variable in the analysis that is performed on academic self-efficacy, Model 2 was adjusted to include a limited set of control variables. This modified set did not include years the parents have been in the U.S. under family characteristics, and only includes male and extra-curricular activities under student characteristics. Adjusted mean differences for all parental engagement variables were included in the table only when the parental engagement variable was a significant predictor of the dependent variable.

\section{Academic Self-Efficacy}

Table $\mathrm{N}$ in the Appendix shows the adjusted mean differences in native language groups for Study efficacy. Models 1 and 2 were significant for all parental engagement variables, so native language group differences were explored for each variable. As indicated in the table, the impact of interaction on a student's Study efficacy is 1.25 units greater for students whose parent speaks West/South Asian than for those students whose parent speaks English.

Table $\mathrm{O}$ displays the adjusted mean differences in native language groups for Math efficacy. Resources is a significant predictor of Math efficacy in Models 1 and 2, and interaction significantly predicts Math efficacy in Model 1. Therefore, the differences between native language groups were explored for these models. 
There were significant differences between Spanish, West/South Asian, and Pacific/Southeast Asian. In the first model, the impact of resources on Math efficacy is 1.56 units greater for students whose parent's native language is West/South Asian than for those students whose parent speaks Spanish. Additionally, the impact is 1.03 units greater for students whose parent speaks Pacific/Southeast Asian than students whose parent speaks Spanish. Also reported in the first model, the impact of interaction on Math efficacy is 1.66 units greater for students whose parent speaks West/South Asian than for students whose parent's native language is Spanish. The impact is also .97 unit greater for students whose parent speaks Pacific/Southeast Asian than those students whose parent speaks Spanish. Table O in the Appendix displays these numbers.

Differences between native language groups are observed for limited models when English efficacy was measured, as noted in Table $\mathrm{P}$ in the Appendix. Interaction is a significant predictor of English efficacy in Models 1 and 2, and resources significantly predicts English efficacy in Model 1, so the differences between native language groups were investigated for these models. The only significant differences were found in Model 1, when interaction was the parental engagement variable. The impact of interaction on a student's English efficacy is 1.28 units greater for students whose parent speaks West/South Asian than for those students whose parent speaks Spanish. The impact is also 1.47 units greater for students whose parent speaks West/South Asian than for students whose parent's native language is Pacific/Southeast Asian. 


\section{General Observations}

See Tables $\mathrm{N}$ through $\mathrm{P}$ in the Appendix for the numerical bases of these observations. It is interesting that only one significant difference was present when parental engagement was run on Study efficacy. It is also interesting that significant differences when resources was the parental engagement variable appeared only when it was run on Math efficacy. Differences were evaluated for rules on efficacy only on the measure of Study efficacy, and even then, no significant differences were found. There were no significant differences between European and any other native language group. When significant differences appeared in all three measures of efficacy, West/South Asian always had a greater impact on efficacy than the alternate native language group. Likewise, Spanish always had a lower impact on efficacy than the alternate native language group.

\section{Educational Attainment Expectation}

The results of the native language comparisons when educational attainment expectation was the dependent variable are found in Table Q in the Appendix. The impact of each parental engagement variable on expectation was found to be significant in both models, when native language was the only control and when the full set of family and student characteristics were added as controls. Therefore, differences in the adjusted means of native language groups were explored for all models.

When resources was the parental engagement variable, significant differences were found between native language groups in both models. The numerical differences are found in Table $Q$ in the Appendix. Within the first model, resources has a greater 
impact on a student's attainment expectation when the student's parent's native language is English, West/South Asian, or Pacific/Southeast Asian than Spanish. Specifically, the impact of resources on expectation is .54 unit greater for English, .92 unit greater for West/South Asian, and .77 unit greater for Pacific/Southeast Asian. Also within the first model, the impact of resources on expectation is .39 unit greater for students whose parent speaks West/South Asian than for students whose parent speaks English. In the second model, the impact of resources on expectation is .42 unit less for students whose parent's native language is Pacific/Southeast Asian than those students whose parent's native language is Spanish.

Similar differences existed when rules was the parental engagement variable, as seen in Table Q in the Appendix. In Model 1, the impact of rules on a student's attainment expectation is greater for students whose parent's native language is English, West/South Asian, or Pacific/Southeast Asian that it is for those students whose parent speaks Spanish. Specifically, the impact is .56 unit greater for English, .97 unit greater for West/South Asian, and .75 unit greater for Pacific/Southeast Asian. The impact of rules on expectation is also .41 unit greater for students whose parent speaks West/South Asian than English. In Model 2, the impact of rules on expectation is .49 unit greater for students whose parent speaks West/South Asian than those students whose parent speaks Spanish, and .48 unit greater for those students whose parent speaks Pacific/Southeast Asian than it is for students whose parent's native language is Spanish.

When observing the lower third section of Table Q in the Appendix, similar differences between native language groups were again found when interaction was the parental engagement variable. In Model 1 , interaction has a greater impact on 
expectation when the student's parent speaks English, West/South Asian, or Pacific/Southeast Asian than it does on students whose parent speaks Spanish. Specifically, the impact of interaction on expectation is . 51 unit greater for English, .92 unit greater for West/South Asian, and .71 unit greater for Pacific/Southeast Asian. Also in Model 1, the impact of interaction on expectation was .41 unit greater for students whose parent speaks West/South Asian than those students whose parent's native language was English, and the impact was .57 unit greater for students whose parent speaks West/South Asian than for those students whose parent speaks a non-English and non-Spanish European language. In Model 2, the impact of interaction on expectation is .55 unit greater for students whose parent speaks West/South Asian and .53 unit greater for students whose parent speaks Pacific/Southeast Asian than those students whose parent speaks Spanish.

\section{General Observations}

See Table $\mathrm{Q}$ in the Appendix for the numbers that support these observations. In the first model, when native language was the only control with the parental engagement variable, the groups of English, West/South Asian, and Pacific/Southeast Asian always had greater impacts on educational attainment expectation than Spanish, and West/South Asian always had a greater impact than English. Pacific/Southeast Asian always had a greater impact than Spanish in the second model, and West/South Asian had a greater impact than Spanish only when rules and interaction were the parental engagement variables. Differences were found with European only when interaction was run on expectation with native language as the only control variable. Overall, there were 
significant findings in the statistical analyses performed in this study. The results will be discussed further in the next chapter. 


\section{CHAPTER V}

\section{DISCUSSION AND CONCLUSION}

\section{Hypotheses}

Based on the statistical analyses, the hypotheses were mostly supported. Parental engagement, measured as resources, rules, and interaction, was found to significantly and positively impact academic self-efficacy and educational attainment expectation, which supports the first two hypotheses. There are some nuances in the impact of parental engagement on efficacy. All three measures of parental engagement were significant predictors of Study efficacy. The impact of engagement varied for Math and English efficacy. Resources was the only significant predictor of Math efficacy and significantly predicted English efficacy only when family characteristics were controlled. Interaction was always a significant predictor of English efficacy. Rules was never found to be a significant predictor of English efficacy.

As hypothesized, the impact of parental engagement on academic self-efficacy and educational attainment expectation differed between native language groups. For the efficacy measures, the differences were seen in the first model, when native language was the only control variable added to the parental engagement variable. When expectation was measured, significant differences appeared between English and other native language groups when the relationship between parental engagement and expectation, without controls, was considered. Most often, the impact of all parental 
engagement variables on academic self-efficacy and educational attainment expectation was greater for West/South Asian and Pacific/Southeast Asian native language groups than Spanish.

The results partially support the hypothesis suggesting that the impact of resources and rules on both efficacy and expectation would be greater for East Asian families. Significant differences were not present between Pacific/Southeast Asian and all of the other native language groups when measuring efficacy and expectation, so conclusions could not be drawn across the board. However, when a significant difference existed between Pacific/Southeast Asian and another native language group, the impact of resources or rules on efficacy and expectation was greater for Pacific/Southeast. The hypothesis suggesting that the impact of interaction on efficacy and expectation would be greater for Spanish families was not supported with the data. When significant differences existed, the impact of interaction on efficacy and expectation was always less for Spanish than any other native language group.

\section{Discussion}

The findings from the statistical analyses emphasize the importance of studying process indicators of academic achievement. Previous literature showed that parental engagement predicts achievement, and this study exposed the deeper relationship between parental engagement and achievement. Academic self-efficacy and educational attainment expectation help explain the process between parental engagement and student achievement. Efficacy and expectation contribute to the end result of achievement. They also help tell the larger story as process indicators of achievement. 
There are some basic explanations to the overall findings of the impact of parental engagement on academic self-efficacy. Resources help students with schoolwork, so they might motivate students to study without the students even realizing the influence. Resources also contribute to students understanding schoolwork and classroom content. This may lead to students' confidence in the subjects of math and English. It is no surprise that there is a link between rules and Study efficacy - rules motivate students to study because they require students to study. While rules require students to work on schoolwork, they don't lead students to feel confident in the school subjects that they study. Communication between parents and children leads students to study because parents might express their belief that education is important and encourage their children to study and work hard in school. Parents might also verbally set expectations for good grades, which motivate students to study. It is interesting that interaction impacts students' confidence in English class and not math class. The English proficiency of parents might explain this finding - parents who speak English are able to help their student with English class. Unfortunately, the analyses did not reveal the direction of the relationship between interaction and English efficacy, and parent's English proficiency was not included as a control variable.

The impact of parental engagement on educational attainment expectation can also be explained with basic reasoning. Resources connect the school and home environments, and students may interpret this to mean that education continues past high school. Rules teach students that school and gaining an education is important, which encourages them to hold a higher attainment expectation. Interaction allows parents to 
directly communicate with students the value of education and their attainment expectations for their children.

Delving further into the interesting analyses results, some findings deserve discussion about how they can be explained on a broader scale. First, the link between resources and income was not significant across the board, which is contrary to previous literature that connects in-home resources to socio-economic status. Given the background, we would always expect income to influence the number of resources found in households. The data in this study shows that resources leads to efficacy, as a whole, but it does not matter how many resources are necessary to change a student's efficacy. Therefore, income does not influence the impact of resources on efficacy. The variable can be related to resources, but is not related to the impact that resources has on efficacy.

Further, the interaction of resources and income is surprising when the dependent variable is attainment expectation. One might assume that income would have a positive interactive effect on resources because income often predicts the number of resources in a student's home. The finding tells us that the influence of resources on expectation is less important for students who come from a family with a higher income. We know that, as a whole, resources has a positive impact on expectation. Parents have created a space where education is present outside of school, and this leads students to believe that education is important. There is no surprise that students with all four resource types hold a higher expectation than students who have little to no access to an in-home learning environment. 
Based on this explanation, we can interpret the interactive effect of income and resources as an understanding of the degree of importance that resources has on expectation for students who come from families with varying incomes. Perhaps students in wealthier families are impacted greater by variables that are different than resources when setting their attainment expectation. Conversely, students in families with lower incomes may rely on the influence of resources when understanding that education is important.

Another interesting finding involves the control variables reporting the number of years the parents have been in the United States. Previous literature indicates that the number of years immigrant parents have been in the U.S. has an effect on their parenting styles. Acculturation into U.S. society often lead parents to adapting parenting styles of native parents, so it would be expected that significant findings would be visible in this study. Individually, the number of years the parents were in the U.S. had no significant effect on attainment expectation and academic self-efficacy. Community aspects may help explain this finding - families in this sample might live in ethnic enclaves in which their native culture persists and native U.S. culture is rejected.

However, the variables indicating length of time parents have been in the U.S. influenced the impact of interaction on attainment expectation and Math efficacy. The impact increases as the number of years in the U.S. increases, and this might occur because the parents' English proficiency improves the longer they live in the country. Portes and Rumbaut (2006) might argue that this occurs when the student has adopted selective acculturation - adhering to different cultural aspects of the U.S. and the 
parent's home country. If the student speaks English, the parent is able to communicate more effectively and influence the student if she speaks English as well.

Differences in native language groups were found when the impact of rules was analyzed on educational attainment expectation. The findings of this analysis support the literature that describes Asian parents as placing more emphasis on rules and rigorous extra-curricular academic work than other ethnic groups, and their children hold high attainment expectations. These rules send messages to children - they set expectations and place a high value on education. Asian children respond to these messages by holding a similar attainment expectation of themselves.

\section{Further Research}

The scope of my study is part of a larger story that explains students' academic experiences. Multiple entities, including parents, influence students toward different process indicators, such as academic self-efficacy and educational attainment expectation, which ultimately lead to academic achievement. Because the study focused on parental engagement for high school sophomore students, it was necessary to exclude additional factors that contribute to academic self-efficacy and educational attainment expectation. The story explaining the way a student's academic self-efficacy and educational attainment expectation are formulated is complex. Several variables pertaining to the student's home environment and school involvement served as controls in order to isolate the relationship between parental engagement and the dependent variables, but numerous variables could have been added. The study aimed to understand student perception of parental engagement on self-efficacy and attainment 
expectation, so many variables came from the student survey. Demographic variables of the student's home environment originated from the parent survey.

Variables deriving from the teacher and librarian surveys of ELS:2002, as well as school characteristics, were excluded because they departed from the focus of student perception. Understanding the teacher's perception, student grades, and school characteristics would be useful in further development of this study. School administrators who want to develop strategies for improving the academic experience of immigrant students could use the supplementary surveys to study additional contributing factors.

Community dynamics were excluded because they also abandoned the focus on student perception of parental engagement, efficacy, and expectation. Based on the results of this study, though, community aspects would have been important to include because they might directly relate to parental engagement. As discussed above, the variable reporting the number of years the parents have been in the U.S. did not influence the impact of parental engagement on efficacy and expectations as was expected, which leads to questions about the relationship between families and community.

This study could be expanded by longitudinally observing the impact of parental engagement on efficacy and expectation. The ELS:2002 data set provides the information from multiple waves of the national study. Changes in students' perception of parental engagement and academic self-efficacy could be observed. Students' actual educational attainment could be discovered in later waves. The ELS:2002 lends itself to expanding the study into students' young adulthood. 
As discussed above, rules had a unique position in the results. It was the only parental engagement variable that included limited control variables in the efficacy analyses, and even with the trimmed models, rules was only a significant predictor for Study efficacy. Additionally, there were no significant differences when comparing the impact of rules on Study efficacy between native language groups. It would be useful to explore the relationship between parental rules and academic self-efficacy in further research.

\section{Conclusion}

Overall, in-home resources, household rules, and parental interaction are positive indicators of academic self-efficacy and educational attainment expectation for second generation immigrant students. All three parental engagement forms positively influence students into setting higher educational attainment expectations. Immigrant parents successfully send the message to their children that education is important. Immigrant parents often hold high attainment expectations for their children because they believe that education is the gateway to overall success in the United States. The presence of in-home resources, household rules, and interaction through communication help these parents convey their high value of education to their children.

Parental engagement impacts academic self-efficacy in different ways for immigrant children. Like expectation, resources positively influences all three measures of efficacy, indicating that the presence of resources in the home should always be encouraged by educators. Perhaps schools can make computers and books available for at-home use, and encourage parents to utilize these opportunities. Rules and interaction 
help motivate students to study. The motivation for students to study could be related to the high value placed on education by immigrant parents. Parents transmit their educational beliefs to their children through their academic engagement with their children.

Discussion throughout this study, as well as prior literature, shows that immigrant parents hold a high value of education and desire for their children to succeed in school. These educational principles guide immigrant parents in their academic engagement with their children. Consequently, students respond favorably and are highly influenced by parental engagement.

These results provide useful information for U.S. schools as they educate increasing numbers of immigrant children. Fortunately, second generation immigrant students are able to have such positive academic experiences in the U.S. education system, despite encountering cultural differences at home. The impact of the home environment has positive results in a different environment, suggesting that students are able to navigate between the different settings.

Educators can use the information garnered from this study to help immigrant parents improve their child's academic experiences, beginning with supporting parents in the engagement forms that are wielding positive results. By understanding the different ways that parents influence their children in school, educators can help parents by personalizing their support of the parents. For example, if many East Asian parents are going to give their children outside academic work, teachers can provide or recommend useful workbooks or computer programs that complement the school coursework. 
This study found that rules and interaction do not impact Math efficacy, and rules does not impact English efficacy. Immigrant parents may transmit their high value of education to their children, but that does not necessarily help students feel confident in their understanding of class content. Schools can help immigrant parents encourage their children to develop a positive self-efficacy for school subjects. Personal communication between teachers and parents or seminars led by schools can teach immigrant parents how to promote students' self-confidence in school.

This study has revealed powerful relationships between parental engagement, academic self-efficacy, and educational attainment expectation for second generation immigrant students. It has provided data on important aspects of a student's academic experience, and offered opportunities for educators to connect with immigrant families. The study has also allowed for expanded research in the future, with the hope that the academic experiences of immigrant students will lead to a positive future amid the changing demographics of the United States. 


\section{REFERENCES}

Alexander, Karl L., and Martha A. Cook. 1979. "The Motivational Relevance of Educational Plans: Questioning the Conventional Wisdom." Social Psychology Quarterly. 42(3):202-213.

Andres, Lesley, Maria Adamuti-Trache, Ee-Seul Yoon, Michelle Pidgeon, Jens Peter Thomsen. 2007. "Educational Expectations, Parental Social Class, Gender, and Postsecondary Attainment: A 10-Year Perspective." Youth and Society. $39(2): 135-163$.

Arnett, Jeffrey Jensen. 1995. "Broad and Narrow Socialization: The Family in the Context of a Cultural Theory." Journal of Marriage and the Family 57(3):617628.

Astone, Nan Marie and Sara S. McLanahan. 1991. "Family Structure, Parental Practices and High School Completion." American Sociological Review. 56(3):309-320.

Baker, David P. and David L. Stevenson. 1986. "Mothers' Strategies for Children's School Achievement: Managing the Transition to High School." Sociology of Education. 59(3):156-166. 
Bandura, Albert. 1977. "Self-efficacy: Toward a Unifying Theory of Behavioral Change." Psychological Review. 84(2):191-215.

Bandura, Albert. 1986. Social Foundations of Thought and Action: A Social Cognitive Theory. Upper Saddle River, NJ: Prentice Hall.

Bandura, Albert. 1994. Self-Efficacy: The Exercise of Control. New York: Freeman.

Beal, Sarah J. and Lisa J. Crockett. 2010. "Adolescents' Occupational and Educational Aspirations and Expectations: Links to High School Activities and Adult Educational Attainment." Developmental Psychology. 46(1):258-265.

Biddle, Bruce J. 1986. "Recent Development in Role Theory." Annual Review of Sociology. 12:67-92.

Bong, Mimi. 2008. "Effects of Parent-child Relationships and Classroom Goal Structures on Motivation, Help-seeking Avoidance, and Cheating." The Journal of Experimental Education. 76(2):191-217.

Bowen, Natasha K., Gary L. Bowen, and William B. Ware. 2002. "Neighborhood Social Disorganization, Families, and the Educational Behavior of Adolescents." Journal of Adolescent Research. 17(5):468-490. 
Bozick, Robert, Karl Alexander, Doris Entwisle, Susan Dauber, and Kerri Kerr. 2010. "Framing the Future: Revisiting the Place of Educational Expectations in Status Attainment." Social Forces. 88(5):2027-2052.

Brandt, Elizabeth A. 1992. "The Navajo Area Dropout Study: Findings and Implications." Journal of American Indian Education. 31(2):48-63.

Capps, Randy, Michael Fix, Julie Murray, Jason Ost, Jeffrey S. Passel, and Shinta Herwantoro. 2005. "The New Demography of America's Schools: Immigration and the No Child Left Behind Act." Washington, D.C.: Urban Institute.

Chen, Chuansheng and Harold W. Stevenson. 1995. "Motivation and Mathematics Achievement: A Comparative Study of Asian-American, Caucasian-American, and East Asian High School Students." Child Development. 66(4):1215-1234.

Chhuon, Vichet, Cynthia Hudley, Mary E. Brenner, and Roseanne Macias. 2010. "The Multiple Worlds of Successful Cambodian American Students." Urban Education. 45(1):30-57.

Colvin, Carolyn and Linda Kramer Schlosser. 1997. "Developing Academic Confidence to Build Literacy: What Teachers Can Do." Journal of Adolescent and Adult Literacy. 41(4):272-281. 
Cooley, Charles Horton. 1902. Human Nature and the Social Order. New York: Scribner.

Delgado-Gaitan, Concha. 1992. "School Matters in the Mexican-American Home: Socializing Children to Education." American Educational Research Journal. 29(3):495-513.

Driscoll, Anne K., Stephen T. Russell, and Lisa J. Crockett. 2008. "Parenting Styles and Youth Well-being Across Immigrant Generations." Journal of Family Issues. 29(2):185-209.

Eccles, Jacquelynne S., Bonnie L. Barber, Margaret Stone, and James Hunt. 2003. "Extracurricular Activities and Adolescent Development." Journal of Social Issues. 59(4):865-889.

Eccles, Jacquelynne S., Allan Wigfield, and Ulrich Schiefele. 1998. "Motivation to Succeed." Handbook of Child Psychology. 5(3):1017-1095.

Elley, Warwick B. 1992. How in the World Do Students Read? Hamburg, Germany: Grindeldruck GMBH. 
Ewell, Peter T. and Dennis P. Jones. 1993. "Actions Matter: The Case for Indirect Measures in Assessing Higher Education's Progress on the National Education Goals." The Journal of General Education 42(2):123-148.

Feliciano, Cynthia. 2005. "Does Selective Migration Matter? Explaining Ethnic Disparities in Educational Attainment among Immigrants' Children." International Migration Review. 39(4):841-871.

Fong, Stanley L. M. 1997. "Assimilation and Changing Social Roles of Chinese Americans." Journal of Social Issues 29(2):115-127.

Ginsburg, Golda S. and Phyllis Bronstein. 1993. "Family Factors Related to Children's Intrinsic/Extrinsic Motivational Orientation and Academic Performance." Child Development. 64(5):1461-1474.

Gonzalez-DeHass, Alyssa R., Patricia P. Willems, and Marie F. Doan Holbein. 2005. "Examining the Relationship Between Parental Involvement and Student Motivation." Educational Psychology Review. 17(2):99-123.

Gottfredson, Linda S. 1981. "Circumscription and Compromise: A Developmental Theory of Occupational Aspirations." Journal of Counseling Psychology. 28(6):545-579. 
Greene, Stuart and Joyce F. Long. 2011. "Flipping the Script: Honoring and Supporting Parent Involvement." Pp. 15-26 in Bedtime Stories and Book Reports: Connecting Parent Involvement and Family Literacy, edited by C. Compton-Lilly and S. Greene. New York: Teachers Press.

Grieco, Elizabeth M., Yesenia D. Acosta, G. Patricia de la Cruz, Christine Gambino, Thomas Gryn, Luke J. Larsen, Edward N. Trevelyan, and Nathan P. Walters. 2012. "The Foreign-Born Population in the United States: 2010." Washington, D.C.: U.S. Census Bureau.

Grolnick, Wendy S. and Maria L. Slowiaczek. 1994. "Parents' Involvement in Children's Schooling: A Multidimensional Conceptualization and Motivational Model." Child Development. 65(1):237-252.

Hao, Lingxin and Melissa Bonstead-Bruns. 1998. "Parent-Child Differences in Educational Expectations and the Academic Achievement of Immigrant and Native Students." Sociology of Education. 71(3):175-198.

Huntsinger, Carol S. and Paul E. Jose. 2009. "Parental Involvement in Children's Schooling: Different Meanings in Different Cultures." Early Childhood Research Quarterly. 24(4):398-410. 
Kao, Grace. 2004. "Parental Influences on the Educational Outcomes of Immigrant Youth." International Migration Review. 38(2):427-449.

Kleitman, Sabina and Jennifer Gibson. 2011. "Metacognitive Beliefs, Self-confidence and Primary Learning Environment of Sixth Grade Students." Learning and Individual Differences. 21(6):728-735.

Lahaie, Claudia. 2008. "School Readiness of Children of Immigrants: Does Parental Involvement Play a Role?" Social Science Quarterly. 89(3):684-705.

Lopez, Gerardo R. 2001. "The Value of Hard Work: Lessons on Parental Involvement from an (Im)migrant Household." Harvard Educational Review. 71(3):416-437.

Louie, Vivian. 2001. "Parents' Aspirations and Investment: The Role of Social Class in the Educational Experiences of 1.5- and Second-Generation Chinese Americans." Harvard Educational Review. 71(3):438-474.

Markus, Hazel and Shinobu Kitayama. 1991. "Culture and the Self: Implications for Cognition, Emotion, and Motivation." Psychological Review. 98(2):224-253.

Markus, Hazel and Paula Nurius. 1986. "Possible Selves." American Psychologist. 41(9):954-969. 
Mau, Wei-Cheng. 1997. "Parental Influences on the High School Students' Academic Achievement: A Comparison of Asian Immigrants, Asian Americans, and White Americans." Psychology in the Schools. 34(3):267-277.

Mead, George Herbert, 1934. Mind, Self and Society. Chicago: University of Chicago Press.

Mello, Zena R. 2008. "Gender Variation in Developmental Trajectories of Educational and Occupational Expectations and Attainment From Adolescence to Adulthood." Developmental Psychology. 44(4):1069-1080.

Moss, Ellen and Diane St-Laurent. 2001. "Attachment at School Age and Academic Performance." Development Psychology. 37(6):863-874.

Mumtaz, Shazia. 2001. "Children's Enjoyment and Perception of Computer Use in the Home and the School." Computers and Education. 36(4):347-362.

Ogbu, John U. and Herbert D. Simons. 1998. "Voluntary and Involuntary Minorities: A Cultural-Ecological Theory of School Performance with Some Implications for Education." Anthropology and Education Quarterly 29(2):155-188.

Ortman, Jennifer M. and Christine E. Guarneri. 2009. "United States Population Projections: 2000 to 2050." Washington, D.C.: U.S. Census Bureau. 
Plunkett, Scott W. and Mayra Y. Bamaca-Gomez. 2003. "The Relationship between Parenting, Acculturation, and Adolescent Academics in Mexican-Origin Immigrant Families in Los Angeles." Hispanic Journal of Behavioral Sciences. 25(2):222-239.

Plunkett, Scott W., Andrew O. Behnke, Tovah Sands, and Brian Y. Choi. 2009. "Adolescents' Reports of Parental Engagement and Academic Achievement in Immigrant Families." Journal of Youth and Adolescence. 38(2):257-268.

Pong, Suet-ling, Lingxin Hao, and Erica Gardner. 2005. "The Roles of Parenting Styles and Social Capital in the School Performance of Immigrant Asian and Hispanic Adolescents." Social Science Quarterly. 86(4):928-950.

Portes, Alejandro and Ruben G. Rumbaut. 2006. Immigrant America: A Portrait. $3^{\text {rd }}$ ed. Berkeley, CA: University of California Press.

Portes, Alejandro and Min Zhou. 1993. "The New Second Generation: Segmented Assimilation and Its Variants." The Annals of the American Academy of Political and Social Science. 530(1):74-96. 
Raghavan, Chemba S., Sara Harkness, and Charles M. Super. 2010. "Parental Ethnotheories in the Context of Immigration: Asian Indian Immigrant and EuroAmerican Mothers and Daughters in an American Town." Journal of CrossCultural Psychology. 41(4):617-632.

Romo, Harriett D. and Toni Falbo. 1996. Latino High School Graduation: Defying the Odds. Austin, TX: University of Texas Press.

Ross-Sheriff, Fariyal, M. Taqi Tirmazi, and Tasanee R. Walsh. 2007. "Cultural and Religious Contexts of Parenting by Immigrant South Asian Muslim Mothers.” Pp. 194-211 in Immigrant Families in Contemporary Society, edited by J.E. Lansford, K. Deater-Deckard, and M.H. Bornstein. New York: Guilford Publications.

Schlosser, Linda Kramer. 1992. "Teacher Distance and Student Disengagement: School Lives on the Margin." Journal of Teacher Education. 43(3):128-140.

Schneider, Barbara and Yongsook Lee. 1990. "A Model for Academic Success: The School and Home Environment of East Asian Students." Anthropology and Education Quarterly. 21(4):358-377.

Schunk, Dale H. 1984. "Self-Efficacy Perspective on Achievement Behavior." Educational Psychologist. 19:48-58. 
Schunk, Dale H. and Carbonari, J.P. 1984. "Self-efficacy Models." In Behavioral Health: A Handbook of Health Enhancement and Disease Prevention, edited by D. Matarazzo, N.E. Miller, S.M. Weiss, J.A. Herd, and S.M. Weiss. New York: Wiley.

Sciarra, Daniel T. and Katherine E. Ambrosino. 2011. "Post-Secondary Expectations and Educational Attainment." Professional School Counseling. 14(3):231-241.

Sewell, William H., Archibald O. Haller, and Alejandro Portes. 1969. "The Educational and Early Occupational Attainment Process." American Sociological Review. $34(1): 82-92$.

Smart, Julie F. and David W. Smart. 1995. "Acculturative Stress of Hispanics: Loss and Challenge." Journal of Counseling and Development. 73(4):390-396.

Stevenson, Harold W., Shin-ying Lee, and James W. Stigler. 1986. "Mathematics Achievement of Chinese, Japanese, and American Children." Science. 231(4739):693-699.

Suarez-Orozco, Carola. 2001. "Afterward: Understanding and Serving the Children of Immigrants." Harvard Educational Review. 71(3):579-589. 
Suarez-Orozco, Carola, Hee Jin Bang, and Marie Onaga. 2010. "Contributions to variations in academic trajectories amongst recent immigrant youth." International Journal of Behavioral Development. 34(6):500-510.

Sue, Stanley and Sumie Okazaki. 1990. "Asian-American Educational Achievements: A Phenomenon in Search of an Explanation." American Psychologist. 45(8):913920.

Topor, David R., Susan P. Keane, Terri L. Shelton, and Susan D. Calkins. 2010. "Parent Involvement and Student Academic Performance: A Multiple Mediational Analysis." Journal of Prevention and Intervention in the Community. 38(3):183197.

Trusty, Jerry. 2000. "High Educational Expectations and Low Achievement: Stability of Educational Goals Across Adolescence." The Journal of Educational Research. 93(6):356-365.

Want, Julie and Sabina Kleitman. 2006. "Imposter Phenomenon and Self-handicapping: Links with Parenting Styles and Self-confidence." Personality and Individual Differences. 40(5):961-971. 
Weiner, Bernard. 1974. "An Attributional Interpretation of Expectancy-value Theory." Pp. 51-69 in Cognitive views of human motivation, edited by B. Weiner. New York; Academic Press.

Zimmerman, Barry J., Albert Bandura, and Manuel Martinez-Pons. 1992. "SelfMotivation for Academic Attainment: The Role of Self-Efficacy Beliefs and Personal Goal Setting." American Educational Research Journal. 29(3):663-676. 


\title{
APPENDIX
}

Table A: Items in Composite Variables

\author{
Academic Self-Efficacy \\ Study \\ I study to get a good job \\ I study to increase my job opportunities \\ When studying, I try to work as hard as possible \\ I study to ensure that my future will be financially secure \\ When studying, I put forth my best effort \\ Math \\ I'm confident that I can do an excellent job on my math tests \\ I'm certain I can understand the most difficult material presented in math texts \\ I'm confident I can understand the most complex material presented by my math teacher \\ I'm confident I can do an excellent job on my math assignments \\ I'm certain I can master the skills being taught in my math class \\ English \\ I'm certain I can understand the most difficult material presented in English texts \\ I'm confident I can understand the most complex material presented by my English teacher \\ I'm confident I can do an excellent job on my English assignments \\ I'm confident I can do an excellent job on my English tests \\ I'm certain I can master the skills being taught in my English class
}

\section{In-Home Resources}

A computer

Access to the Internet

More than 50 books

A room of your own

\section{Interaction}

Selecting courses or programs at school

School activities or events of particular interest to you

Things you've studied in class

Your grades

Plans and preparation for ACT or SAT tests

Going to college

Community, national and world events

Things that are troubling you

\section{Rules}

Check on whether you have done your homework

Require you to do work or chores

Limit the amount of time watching TV/playing video games

Limit the amount of time going out with friends on school nights 
Table B: Frequency and Percentage for Student's Interest in School

\begin{tabular}{lcc}
\hline & Frequency & Percent \\
\cline { 2 - 3 } Not at all & 180 & 7.5 \\
Somewhat & 1485 & 62.1 \\
A great deal & 728 & 30.4 \\
\hline Total & 2393 & $100 \%$ \\
\hline
\end{tabular}

Table C: Descriptives for Control Variables

\begin{tabular}{|c|c|c|c|c|c|c|}
\hline & & $\begin{array}{c}\text { Number of } \\
\text { Dependents } \\
(0-8)\end{array}$ & $\begin{array}{c}\text { Hours of } \\
\text { Extra- } \\
\text { Curricular } \\
\text { Activities } \\
\quad(0-21)\end{array}$ & $\begin{array}{c}\text { Teacher } \\
\text { Influence } \\
(4-16)\end{array}$ & $\begin{array}{c}\text { Peer } \\
\text { Influence } \\
(.33-1) \\
\end{array}$ & $\begin{array}{c}\text { Gender } \\
(0-1) \\
\end{array}$ \\
\hline \multirow[t]{2}{*}{$\mathrm{N}$} & Valid & 2231 & 2289 & 2249 & 2048 & 2514 \\
\hline & Missing & 283 & 225 & 265 & 466 & 0 \\
\hline \multicolumn{2}{|c|}{ Mean } & 3.05 & 3.50 & 11.86 & .828 & .48 \\
\hline \multicolumn{2}{|c|}{ Median } & 3.00 & 1.00 & 12.00 & .778 & .00 \\
\hline \multicolumn{2}{|c|}{ Std. Deviation } & 1.61 & 4.93 & 1.92 & .145 & .50 \\
\hline
\end{tabular}

Table D: Frequency and Percentage for Family

Income

\begin{tabular}{lcc}
\hline \hline & Frequency & Percent \\
\hline$\$ 25,000$ or less & 852 & 33.9 \\
$\$ 25,001-\$ 50,000$ & 808 & 32.1 \\
$\$ 50,001-\$ 100,000$ & 587 & 23.3 \\
$\$ 100,001$ or more & 267 & 10.6 \\
\hline Total & 2514 & $100 \%$ \\
\hline \hline
\end{tabular}


Table E: Descriptives for Length of Time in U.S.

\begin{tabular}{lccc}
\hline & \multicolumn{2}{c}{ Years in U.S. } \\
& \multicolumn{2}{c}{$(0-50)$} \\
\hline $\mathrm{N} \quad$ Valid & 1580 & Father \\
\hline \multirow{2}{*}{ Mean } & Missing & 231 & 599 \\
Median & 19.30 & 104 \\
Std. Deviation & 19 & 19.10 \\
\hline \hline
\end{tabular}

Table F: Frequency and Percentage for Parents' Occupational Status

\begin{tabular}{lcc}
\hline & Mother & Father \\
\hline Full-Time & $935(52.2)$ & $539(77.9)$ \\
Part-Time & $276(15.4)$ & $46(6.6)$ \\
No Job & $579(32.3)$ & $107(15.5)$ \\
\hline Total & $1790(100 \%)$ & $692(100 \%)$ \\
\hline
\end{tabular}

Table G: Frequency and Percentage for Educational Attainment

\begin{tabular}{lcc}
\hline \hline & Mother & Father \\
\hline Did not finish high school & $520(28.7)$ & $153(21.8)$ \\
High school graduate & $342(18.9)$ & $119(16.9)$ \\
Some college & $446(24.6)$ & $148(21)$ \\
College graduate & $351(19.4)$ & $146(20.8)$ \\
Advanced degree & $152(8.4)$ & $137(19.5)$ \\
\hline Total & $1811(100 \%)$ & $703(100 \%)$ \\
\hline
\end{tabular}


Table H: Frequency for Family Composition

\begin{tabular}{lccc}
\hline & Mother & Father & Total \\
\hline Biological Parents & 1193 & 583 & 1776 \\
Mother Only & 429 & - & 429 \\
Father Only & - & 69 & 69 \\
Mother and Male Guardian & 177 & - & 177 \\
Father and Female Guardian & - & 41 & 41 \\
Lives with student less than half the time & 12 & 10 & 22 \\
\hline Total & 1811 & 703 & 2514 \\
\hline
\end{tabular}

Table I: ANOVA Analyses- Parental Engagement on Academic Self-Efficacy and Educational Attainment Expectation

\begin{tabular}{|c|c|c|c|c|c|c|c|c|c|c|c|c|}
\hline & \multicolumn{3}{|c|}{ Study Eff. } & \multicolumn{3}{|c|}{ Math Eff. } & \multicolumn{3}{|c|}{ English Eff. } & \multicolumn{3}{|c|}{ Expectation } \\
\hline & $\underline{N}$ & Mean & $\underline{\text { F-score }}$ & $\underline{N}$ & Mean & F-score & $\underline{\mathrm{N}}$ & Mean & F-score & $\underline{\mathrm{N}}$ & Mean & F-score \\
\hline Resources & 1514 & 9.46 & 4.55 & 1536 & 8.27 & 13.82 & 1572 & 8.72 & 9.17 & 1828 & 5.48 & 51.65 \\
\hline Rules & 1472 & 9.50 & 3.83 & 1494 & 8.29 & .59 & 1525 & 8.74 & 2.16 & 1716 & 5.48 & 4.67 \\
\hline Interaction & 1482 & 9.46 & 13.69 & 1502 & 8.28 & 5.16 & 1534 & 8.72 & 7.29 & 1654 & 5.51 & 10.56 \\
\hline
\end{tabular}

Bold is significant at the .05 level 
Table J: MANCOVA F-scores- Resources on Academic Self-Efficacy

\begin{tabular}{|c|c|c|c|c|c|c|c|c|c|}
\hline \multirow{2}{*}{$\begin{array}{l}\text { Efficacy } \\
\text { Measure } \\
\text { Model }\end{array}$} & \multicolumn{3}{|c|}{ Study } & \multicolumn{3}{|c|}{ Math } & \multicolumn{3}{|c|}{ English } \\
\hline & 1 & 2 & $3+$ & 1 & 2 & $3++$ & 1 & 2 & 3 \\
\hline $\mathrm{N}$ & 891 & 721 & & 891 & 721 & & 891 & 721 & \\
\hline Adjusted Mean & 9.03 & 8.84 & & 7.69 & 7.35 & & 8.51 & 8.54 & \\
\hline Adjusted $\mathrm{R}^{2}$ & .032 & .149 & & .046 & .139 & & .051 & .115 & \\
\hline \multicolumn{10}{|l|}{ Family } \\
\hline \multicolumn{10}{|l|}{ Characteristics } \\
\hline Native Lang. & 1.10 & .23 & & 1.70 & 2.10 & & $4.01^{*}$ & 2.14 & \\
\hline $\begin{array}{l}\text { Occupational } \\
\text { Status }\end{array}$ & .78 & 1.22 & & .43 & .11 & & .48 & .80 & \\
\hline Income & .01 & .15 & & 1.13 & .22 & & .46 & .24 & \\
\hline Mom Educ & 3.44 & .69 & & .92 & .27 & & 5.15 & 2.69 & \\
\hline Dad Educ & .17 & .29 & & .24 & .08 & & 2.51 & 2.67 & \\
\hline Dependents & 5.31 & 1.82 & & 1.49 & .07 & & 2.28 & .27 & \\
\hline Fam Comp & .81 & .28 & & .23 & .46 & & .05 & .07 & \\
\hline Yrs Mom in US & 2.24 & 1.30 & & 1.31 & 1.88 & & .07 & .00 & \\
\hline Yrs Dad in US & .54 & .40 & & .32 & .49 & & .86 & 1.01 & \\
\hline \multicolumn{10}{|l|}{ Student } \\
\hline \multicolumn{10}{|l|}{ Characteristics } \\
\hline Male & & .04 & & & $28.35^{*}$ & & & 3.21 & \\
\hline $\begin{array}{l}\text { Interest in } \\
\text { School }\end{array}$ & & $8.96 *$ & & & $10.74 *$ & & & 6.04 & \\
\hline $\begin{array}{l}\text { Extra-Curr } \\
\text { Activities }\end{array}$ & & 4.03 & & & 1.23 & & & $6.84 *$ & \\
\hline Teacher Inf & & $30.01^{*}$ & & & $7.34^{*}$ & & & 6.34 & \\
\hline $\begin{array}{l}\text { Peer Inf } \\
\text { Interactions }\end{array}$ & & $6.96 *$ & & & $6.26^{*}$ & & & 3.35 & \\
\hline $\begin{array}{l}\text { Resources and } \\
\text { Dad Educ }\end{array}$ & & & 2.64 & & & & & & \\
\hline
\end{tabular}

Bold is significant at the .05 level

Bold $^{*}$ is significant at the .01 level

+ Interactions not sig: Resources paired individually with Male, Income, Native Language, Parent's occupation, Interest in school, Mom educ, Years Mom in US, Years Dad in US

++ Interactions not sig: Resources paired individually with Male, Income, Native Language, Parent's occupation, Interest in school, Mom educ, Dad educ, Years Mom in US, Years Dad in US 
Table K: MANCOVA F-scores- Rules on Academic Self-Efficacy

\begin{tabular}{|c|c|c|c|c|c|c|}
\hline \multirow{2}{*}{$\begin{array}{l}\text { Efficacy Measure } \\
\text { Model }\end{array}$} & \multicolumn{2}{|c|}{ Study+ } & \multicolumn{2}{|c|}{ Math } & \multicolumn{2}{|c|}{ English } \\
\hline & 1 & 2 & 1 & 2 & 1 & 2 \\
\hline $\mathrm{N}$ & 1150 & 1104 & 1150 & 1104 & 1150 & 1104 \\
\hline Adjusted Mean & 9.17 & 9.14 & 8.19 & 8.29 & 8.78 & 8.83 \\
\hline Adjusted $\mathrm{R}^{2}$ & .041 & .055 & .034 & .069 & .042 & .051 \\
\hline Rules & 2.81 * & $2.81^{*}$ & .48 & .35 & 1.34 & .99 \\
\hline \multicolumn{7}{|l|}{ Family Characteristics } \\
\hline Native Lang. & 1.87 & 2.26 & 2.51 & 3.29 & 2.51 & 2.88 \\
\hline Occupational Status & 1.86 & 2.38 & 1.79 & 1.23 & .67 & .65 \\
\hline Income & .14 & .42 & 5.61 & 5.30 & 1.58 & 1.49 \\
\hline Mom Educ & .82 & .15 & .32 & .06 & 3.84 & 3.15 \\
\hline Dad Educ & 2.21 & 1.44 & 5.29 & 4.97 & 4.11 & 2.73 \\
\hline Dependents & $6.95 *$ & $8.28^{*}$ & 1.84 & .46 & 4.90 & 2.73 \\
\hline Fam Comp & 2.67 & 3.13 & .04 & .06 & .16 & .08 \\
\hline \multicolumn{7}{|l|}{ Student Characteristics } \\
\hline Male & & .92 & & $33.02^{*}$ & & $.73^{*}$ \\
\hline Extra-Curr Activities & & $12.97^{*}$ & & 11.48 & & $17.05^{\star}$ \\
\hline
\end{tabular}

Bold is significant at the .05 level

Bold $^{*}$ is significant at the .01 level

+ Interactions not sig: Rules paired individually with Native language, Male, Parent's occupation, Income, Mom educ, Dad educ, Family composition, Dependents 
Table L: MANCOVA F-scores- Interaction on Academic Self-Efficacy

\begin{tabular}{|c|c|c|c|c|c|c|c|c|c|}
\hline \multirow{2}{*}{$\begin{array}{l}\text { Efficacy } \\
\text { Measure } \\
\text { Model }\end{array}$} & \multicolumn{3}{|c|}{ Study } & \multicolumn{3}{|c|}{ Math } & \multicolumn{3}{|c|}{ English } \\
\hline & 1 & 2 & $3+$ & 1 & 2 & 3 & 1 & 2 & $3++$ \\
\hline $\mathrm{N}$ & 873 & 708 & & 873 & 708 & & 873 & 708 & \\
\hline Adjusted Mean & 9.50 & 9.51 & & 8.54 & 8.65 & & 9.08 & 9.18 & \\
\hline Adjusted $\mathrm{R}^{2}$ & .110 & .207 & & .040 & .126 & & .084 & .143 & \\
\hline $\begin{array}{l}\text { Interaction } \\
\text { Family }\end{array}$ & $5.94^{*}$ & $3.98^{*}$ & & 1.57 & 1.35 & & $3.39 *$ & 1.99 & \\
\hline \multicolumn{10}{|l|}{ Family } \\
\hline$\overline{\text { Native Lang. }}$ & .76 & .21 & & 2.12 & 2.53 & & 2.04 & 1.14 & \\
\hline $\begin{array}{l}\text { Occupational } \\
\text { Status }\end{array}$ & .73 & .63 & & .44 & .08 & & .38 & .69 & \\
\hline Income & .02 & 1.47 & & 4.40 & 2.20 & & .28 & .62 & \\
\hline Mom Educ & 1.01 & .04 & & .46 & .48 & & 3.29 & 1.47 & \\
\hline Dad Educ & .26 & .00 & & .06 & .03 & & 1.20 & 2.00 & \\
\hline Dependents & 2.46 & .42 & & 1.68 & .13 & & 1.28 & .01 & \\
\hline Fam Comp & .16 & .48 & & .83 & .85 & & .02 & .04 & \\
\hline Yrs Mom in US & .65 & .52 & & .27 & .86 & & .37 & .35 & \\
\hline Yrs Dad in US & .81 & .99 & & .07 & .28 & & .35 & .45 & \\
\hline \multicolumn{10}{|l|}{$\frac{\text { Student }}{\text { Characteristics }}$} \\
\hline Male & & .01 & & & $26.07^{*}$ & & & 3.21 & \\
\hline $\begin{array}{l}\text { Interest in } \\
\text { School }\end{array}$ & & 7.42* & & & $8.46^{*}$ & & & $6.04^{*}$ & \\
\hline $\begin{array}{l}\text { Extra-Curr } \\
\text { Activities }\end{array}$ & & 2.42 & & & 1.13 & & & $6.84^{*}$ & \\
\hline Teacher Inf & & $25.03 *$ & & & 7.43* & & & 6.34 & \\
\hline Peer Inf & & 4.24 & & & 6.37 & & & 3.35 & \\
\hline Interactions & & & & & & & & & \\
\hline $\begin{array}{l}\text { Interaction and } \\
\text { Income }\end{array}$ & & & 1.77 & & & & & & \\
\hline
\end{tabular}

Bold is significant at the .05 level

Bold* is significant at the .01 level

+Interactions not sig: Interaction paired individually with Native language, Male, Mom educ, Dad educ, Family composition, Dependents, Years Mom in US, Years Dad in US, Interest in school, Teacher influence

++Interactions not sig: Interaction paired individually with Male, Mom educ, Dad educ, Family composition, Dependents, Years Mom in US, Years Dad in US, Interest in school, Income, Teacher influence, Native language 
Table M: ANCOVA F-scores- Parental Engagement Variables on Educational Attainment Expectation

\begin{tabular}{|c|c|c|c|c|c|c|c|c|c|}
\hline \multirow[b]{2}{*}{ Model } & \multicolumn{3}{|c|}{ Resources } & \multicolumn{3}{|c|}{ Rules } & \multicolumn{3}{|c|}{ Interaction } \\
\hline & 1 & 2 & $3+$ & 1 & 2 & $3++$ & 1 & 2 & $3+++$ \\
\hline $\mathrm{N}$ & 1134 & 842 & & 1065 & 788 & & 1018 & 760 & \\
\hline Adjusted Mean & 5.19 & 5.15 & & 5.35 & 5.35 & & 5.43 & 5.42 & \\
\hline Adjusted $\mathrm{R}^{2}$ & .16 & .25 & & .17 & .26 & & .18 & .25 & \\
\hline \multicolumn{10}{|l|}{ Parental Engagement } \\
\hline Resources & $8.60^{\star}$ & $5.32^{\star}$ & & & & & & & \\
\hline Rules & & & & $4.80^{*}$ & $3.87^{\star}$ & & & & \\
\hline Interaction & & & & & & & $5.69^{\star}$ & $2.80^{*}$ & \\
\hline \multicolumn{10}{|l|}{$\begin{array}{l}\text { Family } \\
\text { Characteristics }\end{array}$} \\
\hline Native Lang. & $5.44^{\star}$ & $3.88^{\star}$ & & $7.85^{\star}$ & $5.26^{*}$ & & $9.09^{*}$ & $5.78^{\star}$ & \\
\hline Occ. Status & 1.51 & 3.84 & & 1.63 & 3.41 & . & 3.99 & 4.61 & \\
\hline Income & .52 & .08 & & .30 & .81 & & .01 & .52 & \\
\hline Mom Educ. & $9.13^{*}$ & 5.47 & & $12.98^{*}$ & $6.97^{\star}$ & & $6.98^{\star}$ & 4.62 & \\
\hline Dad Educ. & 1.70 & 1.19 & & 2.67 & 1.41 & & .50 & .16 & \\
\hline Dependents & 2.34 & 1.31 & & 1.75 & .27 & & .91 & .13 & \\
\hline Fam. Comp. & 1.10 & .05 & & 2.73 & 1.36 & & .32 & .03 & \\
\hline Yrs. Mom in US & .17 & .01 & & .81 & .48 & & .30 & .14 & \\
\hline Yrs. Dad in US & .02 & .18 & & .01 & .08 & & .51 & .05 & \\
\hline \multicolumn{10}{|l|}{$\begin{array}{l}\text { Student } \\
\text { Characteristics }\end{array}$} \\
\hline Male & & $22.22^{*}$ & & & $13.62^{*}$ & & & 13.40 & \\
\hline Interest in School & & $5.54^{*}$ & & & $6.87^{*}$ & & & 3.70 & \\
\hline Extra-Curr. Activities & & $23.00^{*}$ & & & $24.05^{*}$ & & & $18.50^{*}$ & \\
\hline Teacher Influence & & 4.40 & & & 2.13 & & & 2.07 & \\
\hline Peer Influence & & $13.56^{*}$ & & & $12.12^{\star}$ & & & $8.31^{*}$ & \\
\hline \multicolumn{10}{|l|}{ Interactions } \\
\hline Par. Eng. and Male & & & 2.55 & & & & & & \\
\hline $\begin{array}{l}\text { Par. Eng. and Native } \\
\text { Lang. }\end{array}$ & & & 1.90 & & & & & & $1.73^{*}$ \\
\hline $\begin{array}{l}\text { Par. Eng. and Par, Ocı } \\
\text { Status }\end{array}$ & & & & & & & & & 1.59 \\
\hline Par. Eng. and Income & & & 2.63 & & & & & & \\
\hline Par. Eng. and Depend & & & 2.93 & & & & & & \\
\hline $\begin{array}{l}\text { Par. Eng. and Fam. } \\
\text { Comp. }\end{array}$ & & & & & & & & & 1.74 \\
\hline $\begin{array}{l}\text { Par. Eng. and Yrs. } \\
\text { Mom in US }\end{array}$ & & & & & & & & & 1.87 \\
\hline $\begin{array}{l}\text { Par. Eng. and Yrs. } \\
\text { Dad in US }\end{array}$ & & & & & & 1.93 & & & $2.28^{*}$ \\
\hline $\begin{array}{l}\text { Par. Eng. and Mom } \\
\text { Educ. }\end{array}$ & & & 2.54 & & & & & & 1.68 \\
\hline
\end{tabular}

Bold is significant at the .05 level

Bold* is significant at the .01 level

+ Interactions not sig: Resources individually paired with Dad educ, Interest in school, Years Mom in US, Years Dad in US 
++ Interactions not sig: Resources individually paired with Native language, Male, Parent's occupation, Income, Dependents, Family composition, Mother educ, Dad educ, Teacher influence

+++ Interactions not sig: Resources individually paired with Male, Income, Interest in school, Dad educ, Dependents, Teacher influence 
Table N: Native Language Comparisons of Parental Engagement on Study Efficacy

\begin{tabular}{|c|c|c|c|c|c|c|c|c|c|c|}
\hline \multirow{4}{*}{$\frac{\text { Model }}{\text { Resources }}$} & \multicolumn{10}{|c|}{ Adjusted Mean Differences (Row - Column) } \\
\hline & \multicolumn{2}{|c|}{ English } & \multicolumn{2}{|c|}{ Spanish } & \multicolumn{2}{|c|}{ European } & \multicolumn{2}{|c|}{ W/S Asian } & \multicolumn{2}{|c|}{$\begin{array}{c}\text { Pac/SE } \\
\text { Asian }\end{array}$} \\
\hline & 1 & 2 & 1 & 2 & 1 & 2 & 1 & 2 & 1 & 2 \\
\hline & & & & & & & & & & \\
\hline English & & & -.18 &. & .12 & .13 & -1.01 & .23 & -.34 & $\overline{0}$ \\
\hline Spanish & & & & & .31 & .33 & -.82 & .43 & -.15 & .16 \\
\hline European & & & & & & & -1.13 & .11 & -.46 &.$\overline{16}$ \\
\hline W/S Asian & & & & & & & & & .67 & .27 \\
\hline $\begin{array}{l}\mathrm{Pac} / \mathrm{SE} \\
\text { Asian } \\
\text { Rules }+\end{array}$ & & & & & & & & & & \\
\hline English & & & -.09 & $\overline{72}$ & .23 & 06 & -1.15 & 101 & -.35 & $\overline{46}$ \\
\hline Spanish & & & & & .33 & .65 & -1.06 & -.30 & -.26 & .25 \\
\hline European & & & & & & & -1.38 & -.95 & -.59 & $\overline{40}$ \\
\hline $\begin{array}{l}\text { W/S Asian } \\
\mathrm{Pac} / \mathrm{SE} \\
\text { Asian } \\
\text { Interaction }\end{array}$ & & & & & & & & & .80 & .55 \\
\hline English & & & -.19 & .10 & .23 & .11 & -1.25 & .02 & -.40 &. \\
\hline Spanish & & & & & .42 & .02 & -1.06 & -.07 & -.20 & .29 \\
\hline European & & & & & & & -1.48 & -.09 & -.62 & .31 \\
\hline W/S Asian & & & & & & & & & .85 & .22 \\
\hline $\begin{array}{l}\mathrm{Pac} / \mathrm{SE} \\
\text { Asian }\end{array}$ & & & & & & & & & & \\
\hline
\end{tabular}

Bold is significant at the .05 level

Bold $^{*}$ is significant at the .01 level

Model 1 includes native language control

Model 2 includes all controls

+ Model 2 includes partial set of controls: Native Language, Occupational Status, Income, Mom educ,

Dad educ, Dependents, Family Composition, Male. Extra-Curricular Activities 
Table O: Native Language Comparisons of Parental Engagement on Math Efficacy

\begin{tabular}{|c|c|c|c|c|c|c|c|c|c|c|}
\hline \multirow[b]{3}{*}{ Model } & \multicolumn{10}{|c|}{ Adjusted Mean Differences (Row - Column) } \\
\hline & \multicolumn{2}{|c|}{ English } & \multicolumn{2}{|c|}{ Spanish } & \multicolumn{2}{|c|}{ European } & \multicolumn{2}{|c|}{ W/S Asian } & \multicolumn{2}{|c|}{ Pac/SE Asian } \\
\hline & 1 & 2 & 1 & 2 & 1 & 2 & 1 & 2 & 1 & 2 \\
\hline \multicolumn{11}{|l|}{ Resources } \\
\hline English & & & .34 & $\begin{array}{c}- \\
.67\end{array}$ & .56 & -.03 & -1.22 & $\begin{array}{c}- \\
.71\end{array}$ & -.69 & $\overline{1.16}$ \\
\hline Spanish & & & & & .22 & .64 & $-1.56^{*}$ & .04 & $-1.03 *$ & -.48 \\
\hline European & & & & & & & -1.78 & $\begin{array}{c}- \\
.68\end{array}$ & -1.25 & $\begin{array}{c}- \\
1.12\end{array}$ \\
\hline W/S Asian & & & & & & & & . & .53 & -.45 \\
\hline \multicolumn{11}{|l|}{$\mathrm{Pac} / \mathrm{SE}$} \\
\hline \multicolumn{11}{|l|}{ Asian } \\
\hline \multicolumn{11}{|l|}{ Rules+ } \\
\hline \multicolumn{11}{|l|}{ English } \\
\hline \multicolumn{11}{|l|}{ Spanish } \\
\hline \multicolumn{11}{|l|}{ European } \\
\hline \multicolumn{11}{|l|}{ W/S Asian } \\
\hline \multicolumn{11}{|l|}{$\mathrm{Pac} / \mathrm{SE}$} \\
\hline \multicolumn{11}{|l|}{ Asian } \\
\hline \multicolumn{11}{|l|}{ Interaction } \\
\hline English & & & .38 & & .78 & & -1.28 & & -.59 & \\
\hline Spanish & & & & & .39 & & $-1.66^{*}$ & & -.97 & \\
\hline European & & & & & & & -2.06 & & -1.37 & \\
\hline W/S Asian & & & & & & & & & .69 & \\
\hline $\mathrm{Pac} / \mathrm{SE}$ & & & & & & & & & & \\
\hline Asian & & & & & & & & & & \\
\hline
\end{tabular}

Bold is significant at the .05 level

Bold* is significant at the .01 level

+ Blank cells indicate that Rules was not a significant predictor of Math Efficacy Model 1 includes native language control

Model 2 includes all controls 
Table P: Native Language Comparisons of Parental Engagement on English Efficacy

\begin{tabular}{|c|c|c|c|c|c|c|c|c|c|c|}
\hline \multirow[b]{3}{*}{ Model } & \multicolumn{10}{|c|}{ Adjusted Mean Differences (Row - Column) } \\
\hline & \multicolumn{2}{|c|}{ English } & \multicolumn{2}{|c|}{ Spanish } & \multicolumn{2}{|c|}{ European } & \multicolumn{2}{|c|}{ W/S Asian } & \multicolumn{2}{|c|}{ Pac/SE Asian } \\
\hline & 1 & 2 & 1 & 2 & 1 & 2 & 1 & 2 & 1 & 2 \\
\hline $\begin{array}{l}\text { Resources } \\
\text { English } \\
\text { Spanish } \\
\text { European } \\
\text { W/S Asian } \\
\text { Pac/SE } \\
\text { Asian } \\
\text { Rules+ } \\
\text { English } \\
\text { Spanish } \\
\text { European } \\
\text { W/S Asian } \\
\text { Pac/SE } \\
\text { Asian } \\
\text { Interaction }\end{array}$ & & & .40 & & $\begin{array}{l}-.19 \\
-.60\end{array}$ & & $\begin{array}{l}-.56 \\
-.97 \\
-.37\end{array}$ & & $\begin{array}{l}-.40 \\
.19 \\
.79 \\
1.16\end{array}$ & \\
\hline English & & & .50 & .05 & -.11 & -.92 & -.78 & .09 & .69 & .45 \\
\hline Spanish & & & & & -.61 & -.87 & $\overline{1.28}$ & .13 & .19 & .49 \\
\hline $\begin{array}{l}\text { European } \\
\text { W/S Asian } \\
\mathrm{Pac} / \mathrm{SE} \\
\text { Asian }\end{array}$ & & & & & & & -.67 & 1.00 & $\begin{array}{c}.80 \\
1.47^{*}\end{array}$ & $\begin{array}{l}1.36 \\
.36\end{array}$ \\
\hline
\end{tabular}

Bold is significant at the .05 level

Bold $^{*}$ is significant at the .01 level

+Blank cells indicate that Rules was not a significant predictor of English efficacy

Model 1 includes native language control

Model 2 includes all controls 
Table Q: Native Language Comparisons of Parental Engagement on Educational Attainment Expectation

\begin{tabular}{|c|c|c|c|c|c|c|c|c|c|c|}
\hline \multirow[b]{3}{*}{ Model } & \multicolumn{10}{|c|}{ Adjusted Mean Differences (Row - Column) } \\
\hline & \multicolumn{2}{|c|}{ English } & \multicolumn{2}{|c|}{ Spanish } & \multicolumn{2}{|c|}{ European } & \multicolumn{2}{|c|}{ W/S Asian } & \multicolumn{2}{|c|}{$\mathrm{Pac} / \mathrm{SE}$ Asian } \\
\hline & 1 & 2 & 1 & 2 & 1 & 2 & 1 & 2 & 1 & 2 \\
\hline \multicolumn{11}{|l|}{ Resources } \\
\hline English & & & $.54^{*}$ & .29 & .08 & .15 & -.39 & -.16 & -.23 & -.13 \\
\hline Spanish & & & & & -.46 & -.14 & $-.92 *$ & -.44 & $-.77 *$ & $-.42 *$ \\
\hline European & & & & & & & -.47 & .30 & -.31 & -.28 \\
\hline W/S Asian & & & & & & & & & .16 & .03 \\
\hline \multicolumn{11}{|l|}{$\mathrm{Pac} / \mathrm{SE}$ Asian } \\
\hline \multicolumn{11}{|l|}{ Rules } \\
\hline English & & & $.56 *$ & .30 & .15 & -.10 & -.41 & -.18 & -.19 & -.18 \\
\hline Spanish & & & & & -.42 & -.41 & $-.97 *$ & -.49 & $-.75^{*}$ & $-.48^{*}$ \\
\hline European & & & & & & & -.55 & -.08 & -.33 & -.07 \\
\hline W/S Asian & & & & & & & & & .22 & .01 \\
\hline \multicolumn{11}{|l|}{$\begin{array}{l}\text { Pac/SE Asian } \\
\text { Interaction }\end{array}$} \\
\hline English & 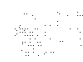 & & $.51^{*}$ & .35 & .16 & .01 & -.41 & -.19 & -.20 & -.17 \\
\hline Spanish & & & & & -.35 & -.34 & $-.92 *$ & -.55 & $-.71 *$ & -.53 \\
\hline European & & & & & & & -.57 & -.21 & -.37 & -.18 \\
\hline W/S Asian & & & & & & & & & .21 & .02 \\
\hline $\mathrm{Pac} / \mathrm{SE}$ Asian & & & & & & & & & & \\
\hline
\end{tabular}

Bold is significant at the .05 level

Bold* is significant at the .01 level

Model 1 includes native language control

Model 2 includes full set of controls 


\author{
CURRICULUM VITAE \\ Casey N. Griffith \\ 1502 Kamer Dr. \\ LaGrange, KY 40031 \\ (502) 552-2990 \\ griffithcn@gmail.com
}

\title{
EDUCATION
}

University of Louisville, Louisville, $\mathrm{KY}$

Graduated, August 2012

- Master's of Arts, Sociology

- Thesis: "Parental Engagement on Student Academic Self-Efficacy and Educational Attainment Expectation for Immigrant Youth"

- GPA 4.0

Belmont University, Nashville, TN

Graduated, May 2008

- Bachelor of Science, Sociology; minor in Business Administration

- GPA 3.5, Cum Laude

\section{TEACHING EXPERIENCE}

\section{Graduate Teaching Assistant}

August 2010-May 2012

Department of Sociology, University of Louisville

- Led a recitation class for a Race in the US course

- Developed course materials

- Graded student work

\section{CONFERENCE PRESENTATION}

"Interpreting Cultural Values in Public Policy: An Examination of Title III in the No Child Left Behind Act."

North Central Sociological Association. Pittsburgh, PA. April 2012.

\section{RESEARCH}

Center for Patient and Professional Advocacy: "All Trauma Surgeons are Not Created Equal: Asymmetric Distribution of Malpractice Claims Risk." Research analyst, podium presentation at the Annual Association for Surgery of Trauma Meeting, October 2009 
PROFESSIONAL EXPERIENCE

Center for Patient and Professional Advocacy, Nashville, TN

Vanderbilt University Medical Center

Client Services Representative I

- Code patient complaint reports.

- Maintain confidential files.

- Produce and revise intervention materials.

- Improve quality assurance through development of current processes.

Shindigs and Celebrations, Nashville, TN

August 2007-June 2008

Sales Associate

- Provided customer service to shoppers in the store.

- Operated cash register and dispensed proper change.

Americana Community Center, Louisville, KY

June 2007-July 2007

Intern/Part Time Summer Youth Program Staff

- Ensured that summer youth program ran smoothly.

- Acted as counselor for a group of eight to ten year old girls.

- Created and implemented art programs.

\section{SKILLS}

Microsoft Office XP: Word, Excel, Access, PowerPoint, Outlook.

SPSS

Interpersonal communication.

Able to work quickly in a high pressure situation. 